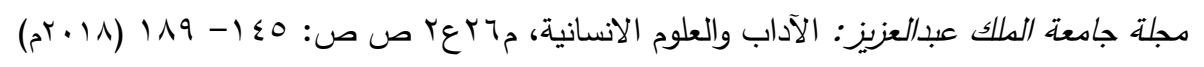

DOI:10.4197 / Art.26-2.8

النظائر المخادعة في تعليم اللغة الأجنبية وتعُُمها

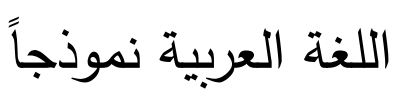

صالح بن عياد الحجوري

جامعة الملك عبدالعزيز

مستخلص: يدرس هذا البحث النظائر المخادعة في تعليم اللغة العربية وتعلّمها، من خلال إطارين: نظري

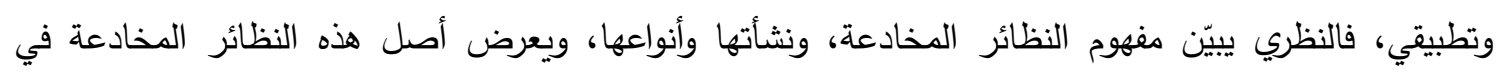

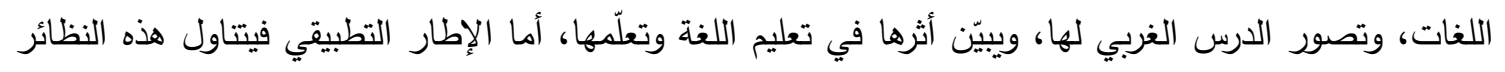

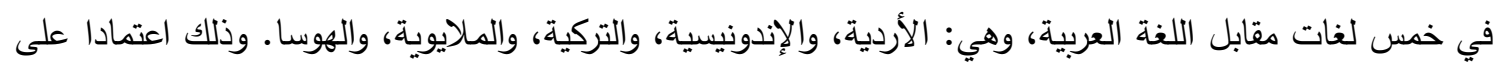

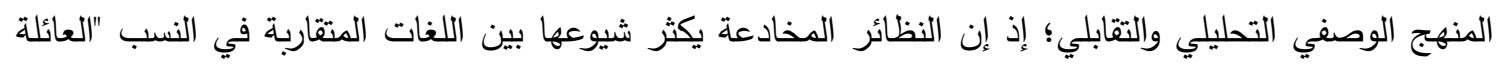

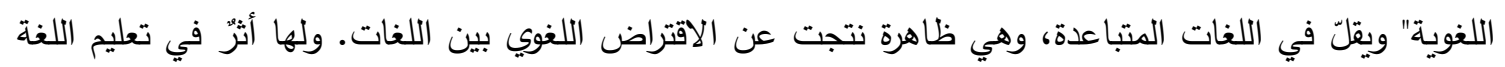
العبية للناطقين باللغات الخمس. الكلمات المفتاحية: النظائر المخادعة - الاقتراض اللغوي- التداخل اللغوي.

ومن أوجه القصور الظاهرة عدم الوقوف عند قضايا المقدمة

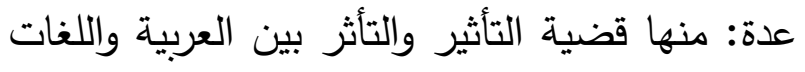
تشهد اللغة العربية اهتماما بالغا، وإقبالا متزايدا على العى الأخرى على مستوى العناصر اللغوية (الأصوات، تعلمها وتعليمها في العالم بأسره، إلا أن تعليمها والمفردات، والتراكيب) لتوظيفها في العملية التعليمية،

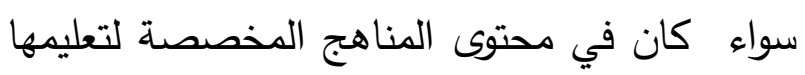
للناطقين بلغات أخرى، أو في إفرادها لبراه المعاجم

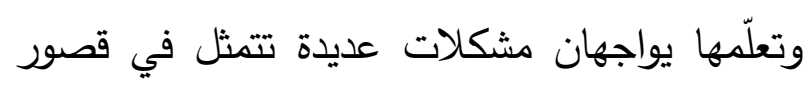
واضح في الأركان الأساسية للعملية التعليمية التي تقوم على: المنهاج، والمعلم، والمتعلم. 
وثانيهما: الإطار التطبيقي الميداني، ويهدف إلى معرفة أثر "النظائر المخادعة" على متعلمي اللغة لإنة العربية الناطقين باللغات الآتية: الأردية، والإندونيسية، والتركية، والملايوية، والهوسا، من الانه خلا إجراء اختبار موضوعي "اختيار من متعدد"،

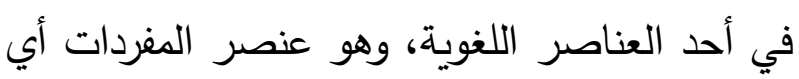

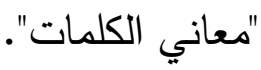

\section{مشكلة البحث وأسئلته}

تتمحور مشكلة البحث في الإجابة عن الأسئلة

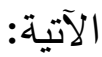

1. ما مفهوم النظائر المخادعة؟ وكيف نشأ هذا

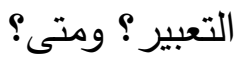

r. ما أصل النظائر المخادعة في اللغات؟ r. هل النظائر المخادعة عامل تيسير على متعلم اللغة العربية من الناطقين بلغات أخرى، أو عامل

تعسير؟

ء. هل للنظائر المخادعة أثر في تعلّم مفردات اللغة العربية لدى متعلميها الناطقين باللغات الخمسة

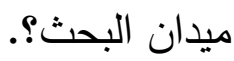
أهمية البحث: - مينان الحث

تتبع أهمية هذا البحث في الناحيتين النظرية والتطبيقية في كونه يقف عند إحدى الظواهر اللغوية الثائعة بين اللغات؛ ليصف هذه الظاهرة ويعرف مدى تأثيرها في تعليم اللغة وتعلّمها، وخصوصًا في لإني

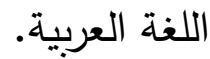

مخصصة للعناصر اللغوية المشتركة في اللغة العربية واللغات الأخرى. من هنا جاءت فكرة البحث في موضوع "النظائر

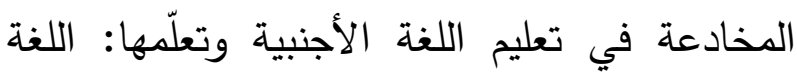
العربية نموذجا". للوقوف عند هذه الظاهرة بالبحث والتحليل وعرض نماذج لها في لغات مختلفة، ومعرفة مدى تأثيرها في تعلّم مفردات اللغة العربية من قبل متعلميها الناطقين بلغات أخرى. وتعود أسباب اختيار هذا الموضوع إلى أهية معرفة "النظائر المخادعة" والوقوف عندها، والإفادة من تلك المعرفة وتوظيفها في وضع المناهج العربية والمعجمات اللغوية التي تيسّر العملية التعليمية على ولى

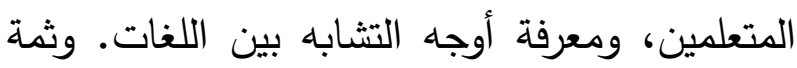
سبب آخر هو عدم وجود دراسات عربية أولت هذه ودين

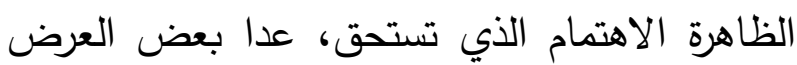

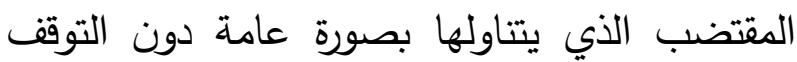

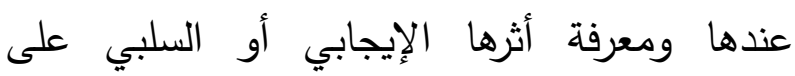

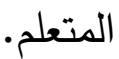

وقد رسدت خطة بحثي على محورين يتناولان إطارين، أولهما: يمثل الإطار النظري، وفيه عرضتُ أربع نقاط، تتناول الأولى: مفهوم النظائر المخادعة، إلهاء ونشأتها، وأنواعها، وتعرض الثاول الاول: معانية: أصل النظائر المخادعة في اللغات، وتبرز الثالثة: النظائر المخادعة في الدرس الغربي. وتعالج الرابعة: أثر النظائر المخادعة في تعليم اللغة وتعلُّمها. 
اللغات المتباعدة. وهذه اللغات تمثل فصائل لغوية متنوعة، كما أن دول الناطقين بهذه اللغات تشهر إقبالًا كبيرًا على تعليم اللغة العربية وتعلّمها. ويكون المستوى التعليمي المستوى الثالث(•). ويقتصر البحث الحالي على عنصر المفردات متمثلا

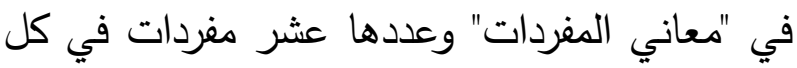
لغة من اللغات الخمس المستهدفة في البحث في معني مقابل اللغة العربية؛ ليصبح مجموع المفردات (خمسين) مفردة في اللغات الخمس يقابلها (خمسون) مفردة في اللغة العربية. أما الاختبار فهو سؤال واحد موضوعي، يتكون من عشر فقرات "اختيار من لنال

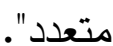

مجتمع البحث: مجتمع البحث هم متعلمو اللغة العربية الناطقون باللغات المذكورة، ويبلغ عددهم (مئة وخمسين) طالبا وطالبة من الناطقين باللغات الخمس المحدة في هذا البحث، بواقع (ثلاثين) متعلما لكل لغة. منهج البحث: يستخدم البحث المنهج الوصفي التحليلي والتقابلي الذي يهتم بوصف الظاهرة اللغوية وتحليلها، وهو يطبق اختبارا على العينة المستهدفة في البحث.

\section{الاراسات السابقة}

لم أقف -فيما اظلّعت عليه من مصادر ومراجع باللغة العربية- على دراسات تناولت موضوع معني

(•) أو ما يقابل (B2) في الإطار المرجعي الأوروبي المشترك لتعليم

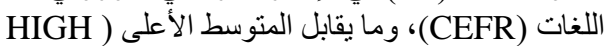
(INTERMEDIATE في إرشادات المجلس الأمريكي لتعليم اللغات (ACL)
حدود البحث: يقتصر البحث على الحدود الآتية: 1. حدود مكانية: طبّق الاختبار على الناطقين باللغة الأردية في مركز تعليم اللغة العربية في الجامعة الإسلامية العالمية في باكستان، وعلى لاطيه الناطقين باللغة الإندونيسية والهوسا في معهد تعليم اللغة العربية لغير الناطقين بها في الجامعة الإسلامية في المدينة المنورة، وعلى الناطقين باللغة التركية (في كلية العلوم الإسلامية بجامعة السلطان

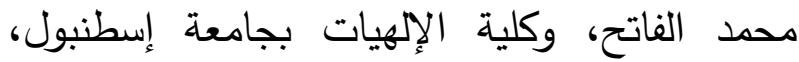

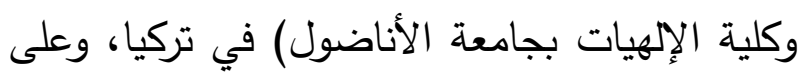
الناطقين بالملايوية في ق قسم اللغة والاتصالجامعة السلطان زين العابدين في مدينة ترنجانو في

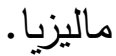
r. حدود زمانية: طبّق الاختبار في الفصل الدراسي

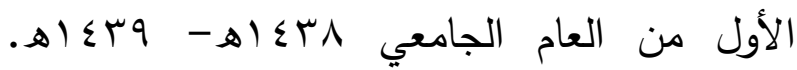
وزمنه نصف ساعة إضافة إلى خمس دقائق لكتابة البيانات وقراءة التعليمات r. المدود موضوعية: يلتزم البحث بالتطبيق على عينة من متعلمي اللغة هوصنه

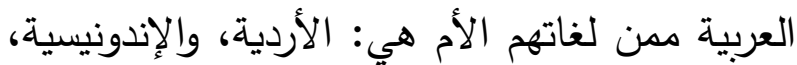
والتركية، والملايوية، والهوسا. ويعود سبب اختيار الهيار هذه اللغات على وجه التحديد إلى أنها تشيع فيها النظائر المخادعة للتأثير والتأثر المتبادل بينها وبين العربية، فكلما كانت اللغات متقاربة ظهرت فيها هذه الظاهرة بشكل جليّ، وربما أدت إلى أخطاء عند متعلميها، في حين أنها لا تظهر بشكل كبير في 
نظري وآخر تطبيقي؛ لمعرفة أثر هذه النظائر على متعلمي اللغة العربية الناطقين بلغات أخرى. وقد عثرتُ على دراسات أجنبية عدّة تتاولت هذا لخدين

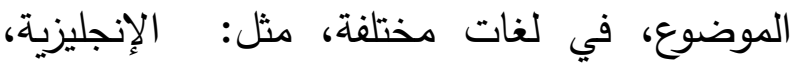
والإسبانية، والفرنسية، والألمانية وغيرها، واستفدت منها كثيرًا وقد خصصت بحثي للغة العربية، وستأتي والئي الإثارة إلى هذه الدراسات في الإطار النظري. المحور الأول: الإطار النظري: أولا: النظائر المخادعة: مفهومها ونشأتها وأنواعها

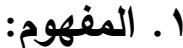

ورد في لسان العرب "جمع النظير : نظراء، والأنثى نظيرة، والجمع النظائر في الكلام والأشياء كلها... والنظائر: جمع نظيرة، وهي المثل والثبه في

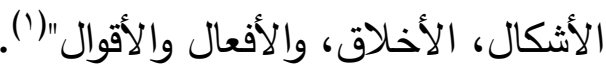
ويتضح من المعنى اللغوي لهذه الكلمة أنها تعني المشابهة التامة لثيء آخر، فالنظير لغة المثل المساوي، وهذا نظير هذا أي مساويه. ويبدو من خلال استعراض المعاني اللغوية للنظائر أن اللغويين جعلوا اللفظين بمعنى واحد وهو المثل، فجاء الاقتران بين اللفظين الأشباه والنظائر. وقد عرّف أحمد الحموي الأشباه والنظائر بأنها: "المسائل التي يشبه بعضها بعضا مع اختلاف في

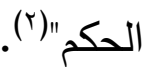

\footnotetext{
(1) (بن منظور، محمد بن مكرم، لسان العرب، طسا، بيروت: دار صادر،

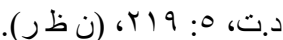

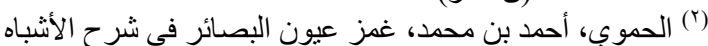

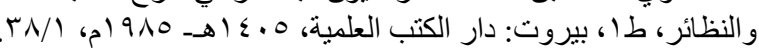

"النظائر المخادعة" بالبحث والدراسة ما عدا مقالًا قصيرًا كتبه خالد أبو عششة، بعنوان:" النظائر المخادعة في تعليم العربية للناطقين بغيرها" على نعلى موقع الجزيرة، ونُقِلَ أيضًا في منتدى مجمع اللغة

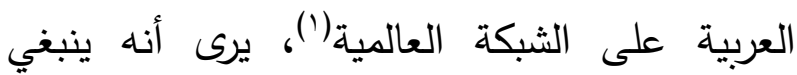
لمدرس اللغة العربية ودارسها أن يحترس من ظاهرة لغوية قد تفضي إلى اللبس وسوء الفهم وهي ظاهرة النظائر المخادعة، وقد عرّج في مقاله على تعريف النظائر المخادعة وأنواعها وأتى ببعض الأمثلة لها، مقتبسًا بعض المعلومات من عبده الراجدي، في كتابه:" علم اللغة التطبيقي وتعليم اللغة، الفصل الرابع: التحليل التقابلي وتحليل الأخطاء"، وأيضًا قد وردت إشارات إلى النظائر المخادعة عند محمود إسماعيل وإسحاق الأمين في كتابهما: "التقابل اللغوي إنساري وتحليل الأخطاء"(؟)، وكذلك عند سويفي فتحي، في بحثه:" أثر التقابل اللغوي في تعليم العربية لغير الناطقين بها"(r). وهذه الدراسات السابقة يلاحظ أنها أشارت إلى النظائر المخادعة إثارة عابرة ولم تقف عندها دراسةً

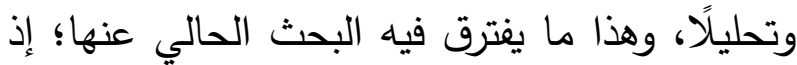
إنه وقف عند النظائر المخادعة من خلال إطار

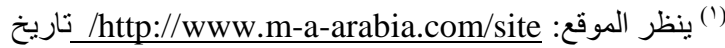

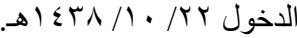

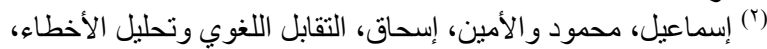

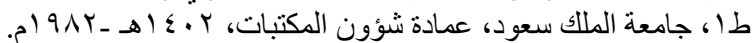

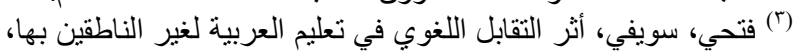

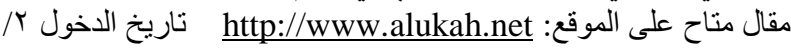

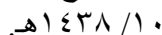


ويعرّف محمود إسماعيل وإسحاق الأمين، النظائر المخادعة بقولهما: "يستعمل التعبير "النظائر

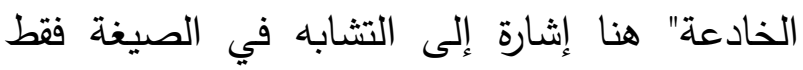
والاختلاف في المعنى، ولا يحمل التعبير إثارات إلى أصل الكلمات، أما في مصطلح علم اللغة فلة، فالتعبير "النظائر الخادعة" يدل عادة على كلمات في اللغتين تبدو مترابطة في الأصل في حين أنها ليست

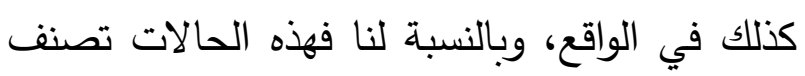
بوصفها نظائر إذا كانت المعاني متشابهة" ('). ونرى استعمال لفظ الخادعة في هذا التعريف بدلًا لوانل

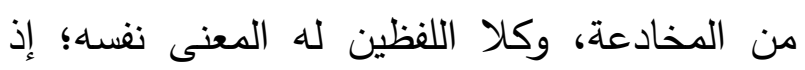
إنهما من مادة واحدة "خدع" وذات مدلول واحد. ويعرّف معجم لونجمان لتعليم اللغات وعلم اللغة مدات

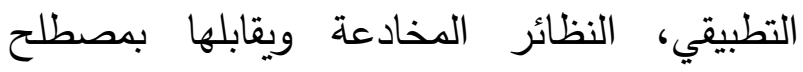

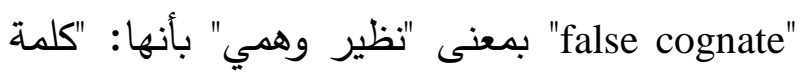

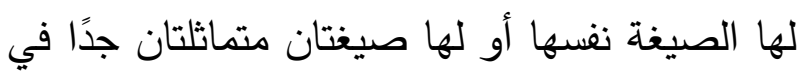
لغتين اثنتين، ولكل منهما معنى يختلف في كل لغة لغنة

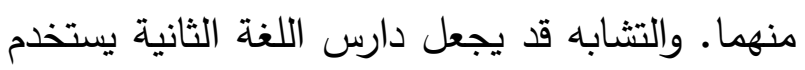
الكلمة استخداما خطأً... ويمكن أن تُعْرفت النظائر الوهمية عن طريق التحليل التقابلي"(؟). ويعرّفها عبده الراجحي بأنها: "تعبير فرنسي أصبح التحئ

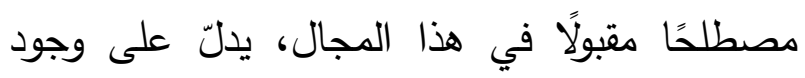
كلمات متشابهة بين لغتين لكنها في الحقيقة مختلفة

(1) (إسماعيل و الأمين، التقابل اللغوي وتحليل الأخطاء، مرجع سابق، ص (1)

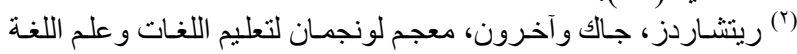

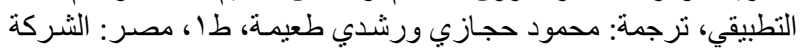

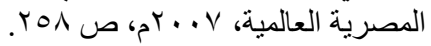

وورد في التراث العربي أسماء مؤلفات تحمل هذا العنوان، سواء في أصول الفقه مثل: كتاب الأشباه والنظائر للإمام صدر الدين بن الوكيل (ت 9 (Y) هـ)،

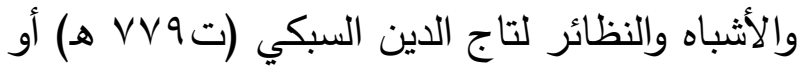
في أصول النحو مثل: كتاب الأشباه والنظائر في النحو لجلال الدين السيوطي (ت التول: (1)هـ). ويعرّف محمود إسماعيل وإسحاق الأمين، النظائر

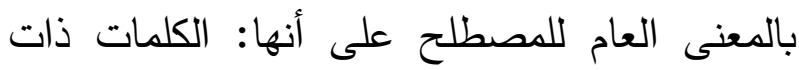
العلاقة في أصلها، ويسميان الكلمتين إذا كانتا متشابهتين في الصيغة والمعنى نظيرين حتى وإن لم

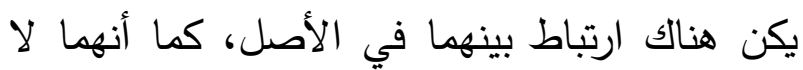
يعدّان الكلمات نظائر وإن كانت من الأصل نفسه إذا إدا اختلفت في معناها الراهن بحيث يختلف المتكلمون

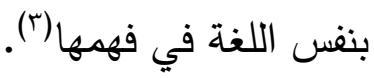
أما المخادعة، فهي من مادة "خدع، وورد في لسان

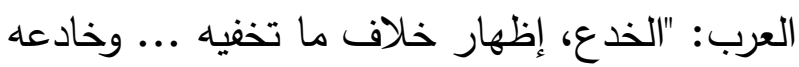
مخادعة وخداعا وخذّعه واختدعه"(\{). ويتضح من معنى المخادعة اللغوي: أن الشيء وخهاء وخداء الظاهر خلاف الخفي، فهذا هو المخادع، وإذا اجتمع الموصوف والصفة أصبحا " النظائر المخادعة" هول وتعني الأشياء المتثابهة في ظاهرها والمختلفة في باطنها وهذا ينطبق تمائًا على مفهوم النظائر المخادعة في تعليم اللغة.

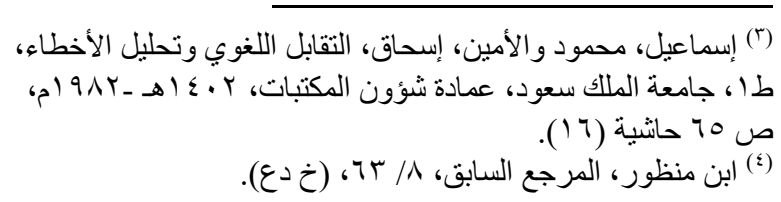


ويقول حسن ظاظا: "وقد خدع بعض الباحثين في اللغات بظاهرة ضللتهم عن ذلك، وهي أنه توجد في

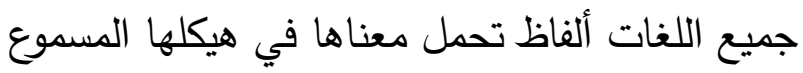
نفسه، أي في جرسها الصوتي، وكأنها تحاكي هات العاطي

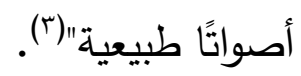
وأرى أن النظائر المخادعة هي تثابه أحد العناصر اللغوية الثلاثة "الأصوات - المفردات - التراكيب" في لغة ما تشابها شكليًا مع لغة أخرى؛ إذ قد توجد الفد في الأصوات، مثل: صوت (ث) الذي تطور في الملايوية إلى صوت (س)، في مثل كلمة (ثابت)

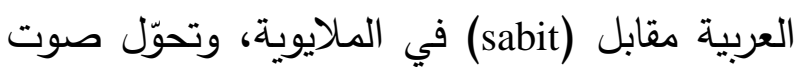
(ظ) إلى (ل) كما في (ظاهر) و (حفظ) العربيتين

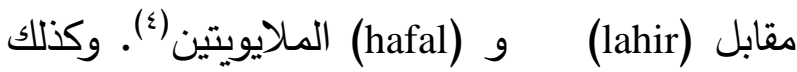
I'm ) على مستوى التراكيب، فمثلا الجملة الإنجليزية (feeling blue أنه يشعر بالحزن والتعب النفسي، وفي المقابل إذا

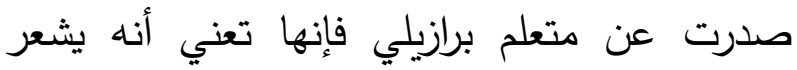

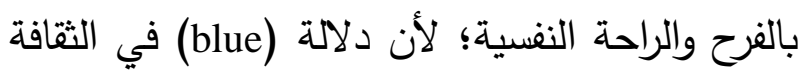
الإنجليزية تختلف عنها في الثقافة البرازيلية. إذن لاندانه اللغة الأم تتذخل بشكل ملحوظ على مستويات: الأصوات، والمفردات، والتراكيب، والد لالة (०).

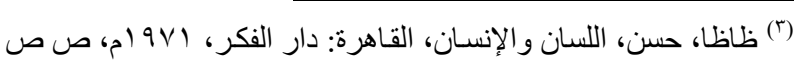

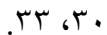

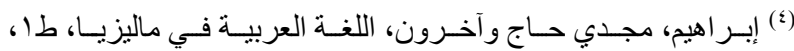

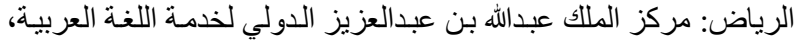
م

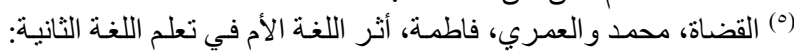

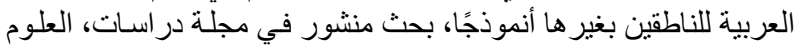

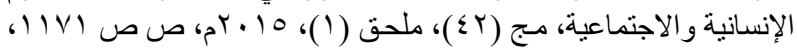

في الاستعمال، وتؤدي إلى أخطاء، ويحدث هذا في

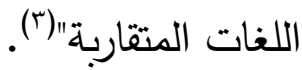
ويعرّفها خالد أبو عمشة بأنها:" زوجان من المفردات من لغتين مختلفتين تتثابهان صونًا وتختلفان

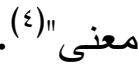
ويذكر البدراوي زهران، أن النظائر المخادعة تعني:

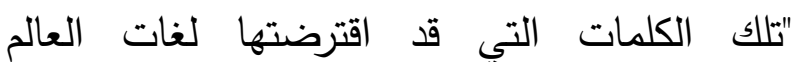

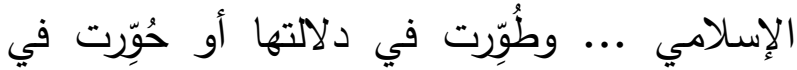
معانيها، ومن هذا فقد تكون الكلمات متشابهة في

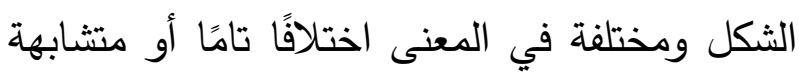

في الشكل وتحمل تشابهًا جزئيًا في كلتا اللغتين"( (1).

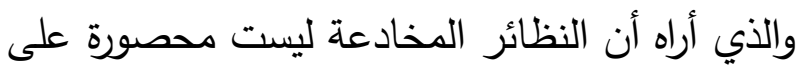
لغات العالم الإسلامي؛ بل إنها توجد في اللغات بصفة عامة. - مان ويفرّق سويفي فتحي، بين الكليات اللغوية والنظائر المخادعة بقوله: "إن التشابه بين العربية وغيرها من اللغات في الكلمات لفظا ومعنى يعرف بالكليات

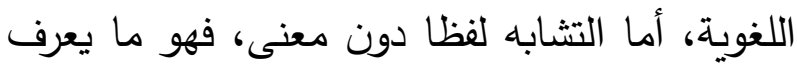

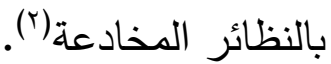

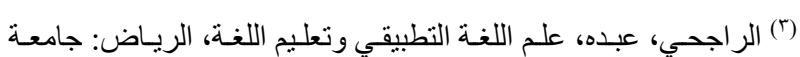

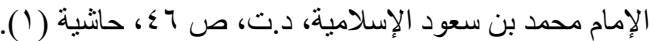

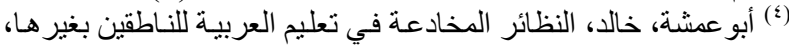

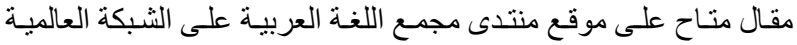

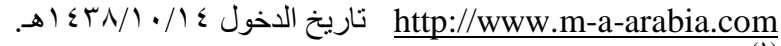

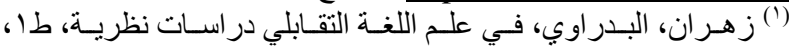

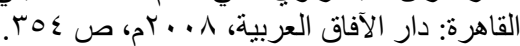

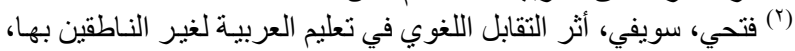
مقال متاح على الموقع: http:/Www.alukah.net ه $1 \leqslant$ ـ / . 1 1 
عنصرا معيّنا في (ل ())، وبينهما في الواقع اختلاف<smiles>[13CH3][13CH2][13CH2][AlH]</smiles>
r. أنواع النظائر المخادعة: يذكر روبرت لادو، أنه بمقارنة مفردات اللغة الأجنبية بمفردات اللغة الأصلية نجد الكلمات تتوزع على النحو الآتي: أ. متشابهة في الصيخة والدلالة.

ب. متشابهة في الصيغة ولكنها مختلفة في الدلالة. ج. متشابهة في الدلالة مختلفة في الصيغة. د. مختلفة في الصيغة والدلالة. هـ مختلفة من حيث نوع البنية. و. متثابهة في الدلالات الأساسية ولكنها مختلفة من حيث إيحاء اتها. ز· متشابهة في الدلالة ولكنها مقيدة من حيث التوزيع الجغرافي (') - (ان. والذي يخصّ البحث من هذه الأنواع النوع الثاني وهو النظير اللفظي، أي مشابهة اللفظ للفظ آخر في اللغة

$$
\text { الأجنبية مع اختلاف المعنى. }
$$

ويصنف بعض الباحثين النظائر المخادعة بالنظر إلى الفروق الدلالية القائمة بين زوجين من الكلمات المتشابهة في لغتين مختلفتين، إلى تتاظر كلي وآخر

(§) Pedro J, Chamizo-Domínguez, Semantics and Pragmatics of False Friends, London: New York Routledge, 2008, p1 and beyond, Tycová, Lenka. Towards a New False Friends Dictionary, Bachelor's Diploma Thesis, Masaryk University; Faculty of Arts, 2012, p8 and beyond.

(') إسماعيل والأمين، التقابل اللغوي وتحليل الأخطاء، مرجع سـابق، ص r . نشأة مصطلح النظائر المخادعة: أشرت سابقا إلى أن عبده الراجحي، يرى أن النظائر المخادعة تعبير فرنسي(') . ويعود استعماله إلى عام

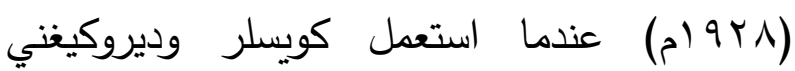
مصطلح النظائر (koessler and Derocquigny) المخادعة "Faux amis" في كتابهما المعروف

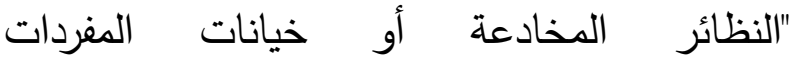
(les Faux Amis, ou les Triahisons du الإنجليزيـة vocabulaire Anglais ( ${ }^{(\top)}$. عبارة عن كلمة في اللغة الثانية تأتي متثابهة لكلمة في اللغة الأولى، تكون المشابهة في الثكل "الهجاء" أو النطق، ولكن المعنى مختلف تمامًا، أو جزئيًا في

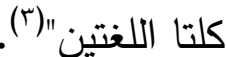

وقد ذكر تشاميزو دومينغويز بيدرو -Chamizoأن ظاهرة النظائر المخادعة Domínguez Pedro) كقضية تداخل لغوي قديمة قدم اللغات الطبيعية نفسها. أما مصطلح "نظائر مخادعة" فإنه جديد نسبيًا، صاغه كويسلر وديروكيغني عام ( 9 (م) عندما استخدما مصطلح "Faux amis" في كتابهما السابق، وقد نشأ هذا المفهوم من فكرة أن عنصرا معجميا معيّنا في (لr) يبدو أن فيه علاقة تعادل

(') الر اجحي، علـم اللغـة التطبيقي وتعليم اللغـة، مرجـع سـابق، ص 7 ــ، حاثية (1). (1).

$\left.{ }^{(}\right)$Look: The Problem of False Friends in Learner Language Evidence from Tow Learner Corpora, Santiago University Learner of English, Published

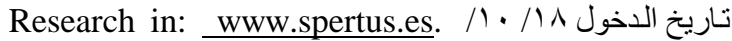
ه $1 \leqslant r \wedge$

(r) The Problem of False Friends in Learner Language Evidence from Tow Learner Corpora, op cit. 
وقد أورد خالد أبو عمشة (๕). نوعين للنظائر

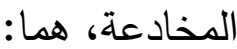

أ. نوع يحدث بسبب ما تقترضه لغة من أخرى، فيتطابق صوتًا ويختلف معنى ودلالة، وذلك مثل كلمة "مسافر" في اللغة العربية و( misafer) في اللغة التركية التي تعني "ضيف". ب. نوع يتطابق صوتًا ولا علاقة البتة فيه بين

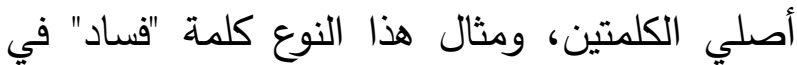
اللغة العربية؛ إذ يقابلها في الإنجليزية تقريبا الصوت نفسه ولكن بمعنى آخر فالكلمتان تتشابهان صوتًا وتختلفان معنى؛ مما قد يلبس على متعلم اللغة العربية ظانًا أن كلمة فساد العربية تعني الواجهة

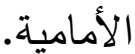
إذن الكلمة إذا انتقلت إلى لغة أخرى قد تتغيّر دلالتها إما جزئًا أو كليًا، مما يسبب لبسا عند استعمال المتعلم لها، فمثلً في العربية والتركية بعض الكلمات العربية احتفظت بجزء من أصل معناها فقط، ومن ذلك كلمة "جزاء" في العربية قد تكون بمعنى الثواب

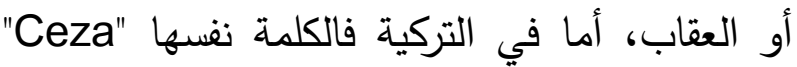

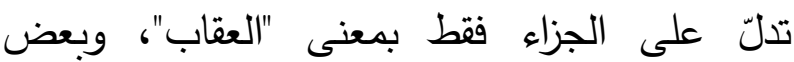
الكلمات العربية الأصل تغيّرت دلالتها تمامًا في ولئي التركية، ومن ذلك كلمة "قفا" في العربية تعني: مؤخرة العنق في حين أنها في التركية بنفس اللفظ العربي "Kafa" لكنها تعني: الرأس (').

(1) عبدالحميد، علي، مشكلات تعليم اللغو العربية لغير الناطقين بها: كليات

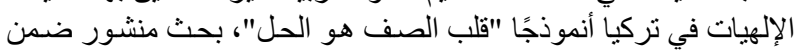

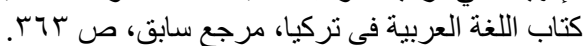

جزئي ومن أمثلة التناظر الكلي كلمة "أفوكادو" في "Avocado" الإنجليزية والإسبانية، ففي الإنجليزية "Abogado" تعني نوعًا من الفاكهة، أما في الإسبانية،

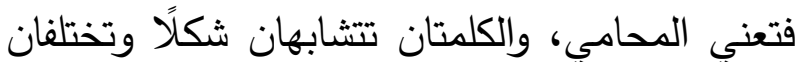
معنى، أما التتاظر الجزئي فإنه يظهر تداخلًا دلاليًا معيًّا، يحدث هذا التداخل عندما يكون لكلمتين متشابهتين معنى مشترك واحد على الأقلّ وواحد مختلف، مثل كلمة "تداول" "circulation" في

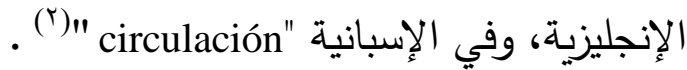
وبيّن روبرت لادو أنواع الكلمات التي تتشابه في الابه أشكالها وتختلف في معانيها؛ إذ "قد تكون الكلمات المتشابهة في الشكل متشابهة تشابهًا جزئيًا في لهابيا المعنى في كلتا اللغتين، كما أنها قد تختلف فيه

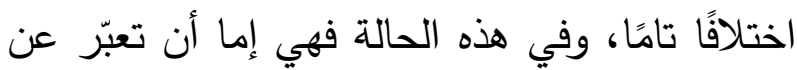
معانٍ في اللغة الأجنبية يدركها الدارس من تجربته

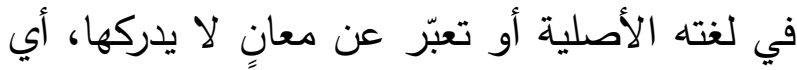
لا تكون جزيًا من تجربته، فالكلمة (milk) مثلاً استعارها اليابانيون من اللغة الإنجليزية ولكنهم قيدوها ] لتعني اللبن "المعلب"، فشكل الكلمة في اللغة الإنجليزية] اليابانية مشابه لشكلها في الإنجليزية، أما لئ التشابه بين الكلمتين من حيث الدلالة فهو تثابه جزئي؛ إذ تشمل الكلمة في اللغة اليابانية اللبن

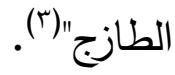

Look: The Problem of False Friends in Learner ( ()

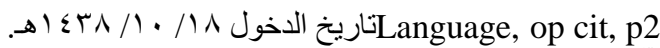

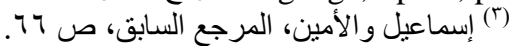
(؛) أبو عشة، النظائر المخادعة في تعليم العربية للناطقين بغير ها، مرجع 
ذهب إلى تقرير هذا التوجه معظم اللغويين ابتداء من سابير (Sapir) حتى هوجن (Haugen) (؟). وقد نالت ظاهرة الاقتراض اللغوي اهتمام العلماء العرب الأوائل بشكل كبير؛ إذ أوجدوا مصطلحات عدة للتعبير عن الاقتراض، منها: الاخيل، والمعرّب،

$$
\text { والمولّد، والأعجمي (') }
$$

وقدّم فقهاء اللغة العربية القدامى والمحدثون أدلة لا تحصى لإثبات أن تبادل التأثير والتأثر بين اللغات قانون اجتماعي إنساني، وإن الاقتراض اللغوي بين اللغات الإنسانية ظاهرة علمية تشمل كل اللغات، فاللغات جميعا تتبادل التأثز والتأثير وهي جميعًا تُقرض وضَتَترض (r) ويكون الاقتراض بين اللغات بطريق مباشر أي أن تكون الكلمة المقترضة أصلية في اللغة المقترض منها، أو غير مباشر بمعنى أن الكلمة المقترضة ليست أصلية في اللغة المقترض منها؛ بل هي مقترضة من لغة أخرى، ومن أمثلتها الكلمات العربية: الجبر ، والكحول اللتان اقترضتهما الإنجليزية

Camel Heah Lee Hasia, (1989), The Influence of (घ) English an the Lexical of Bahasa Malaysia, Kuala Lumpur: Dewan Bahasa dan Pustaka, 1989 p.12.

وينظر : إبر اهيم وآخرون، اللغة العربية في ماليزيا، مرجع سابق، ص (') ينظر على سبيل التمثيل: المعرب من الكلام الأعجمي لأبي منصـور

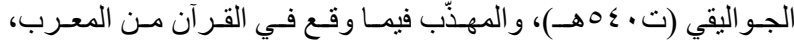

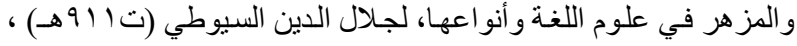

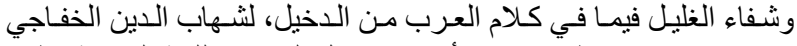

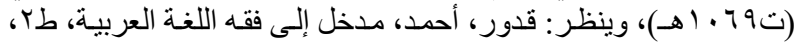

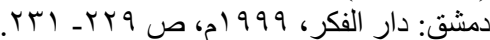

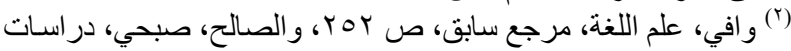

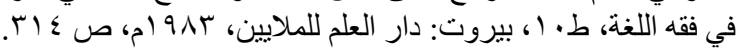

ثانيًا: أصل النظائر المخادعة في اللغات تعذّ المفردات أكثر عناصر اللغة عرضة للتطور والتغيير، وتسلك اللغات في ذلك مسالك عدّة ومتنوّعة، فقد تقتبس لغة من لغة أخرى بعض مفرداتها، على الرغم من عدم وجود صلة قرابة بينهما، فالسريانية اقتبست عددًا كبيرًا من الإغريقية التي تعدّ من أفراد الهند-الأوروبية، في حين أن السريانية من فصيلة اللغات السامية)(؟). ومن المقرر بين اللغويين أن أيّة لغة لا تعيش بمعزل من الاحتكاك بلغة أخرى، كما أنه من المقرر بين علماء الاجتماع أن أي مجتمع لا يعيش بمعزل من الاحتكاك بمجتمع آخر، ويختلف التأثير اللغوي قوة وضعفًا بمدى العلاقات التي تربط بين المجتمعين، وينتج عن هذا الاحتكالك كثير من التغيرات ربما كان أهمها الاقتراض، وهو أخذ عنصر لغوي من لهجة أو لغة وإدخاله في لهجة أو لغة أخرى. ومن المعروف أن المجتمع الذي يتأثر بثقافة مجتمع آخر يقترض الألفاظ التي تعبّر عن هذه الثقافة التي لا نظير لها

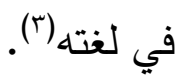
وتتدرج دراسات الاقتراض اللغوي تحت مجال دراسات الاتصال اللغوي (Language Contact)، وبما أن الاتصال اللغوي شكل من أشكال الانتقال الثقافي بين الشعوب، فإن الاقتراض اللغوي يصبح ظاهرة عالمية تشمل اللغات والثقافات جميعا، وقد

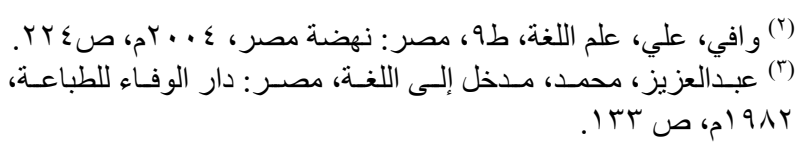


توضح أسباب تغيّر المعنى وتطوره، وهناك ثلاثة تقسيمات يخضع لها تغيّر الدلالة في معظم اللغات وهي التي تعرف بقوانين المعنى أو أشكاله ومظاهره،

أولا: تخصيص الدلالة: ومن أمثلة ذلك، لفظ "أخبار" "akhbar" من معنى الخبر، وهو ما يُنقل ويُحدّث به قولًا أو أو كتابة إلى معنى الجريدة أو الصحيفة التي تتقل وهن لهن الأخبار المكتوبة فقط. ثانيا: تعميم الدلالة: ومن أمثلة ذلك، لفظ "آية" "ayat" والذي يعني في العربية علامة، وقد تحول هذا اللفظ في الإندونيسية إلى معنى الجملة. ثالثا: نقل الدلالة: ومن أمثلة ذلك لفظ "فنجان" "pinggan" الطبق، وكذلك لفظ "إنصاف" "insaf" في الملايوية فقد انتقلت دلالته إلى معنى التوبة. وبجانب هذه التقسيمات الثلاثة لتغيّر الدلالة، ذكر بعض الباحثين تقسيمات أخرى في تقسير جوانب من تطوّر دلالة الألفاظ، مثل: ظاهر انحطاط الدلالة ورقيها، والتطور الدلالي من المحسوس إلى المجرد،

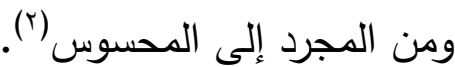

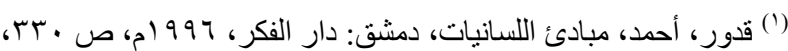

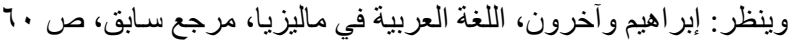

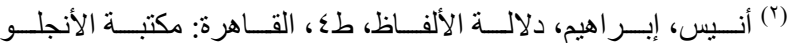

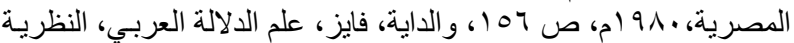

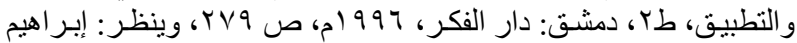

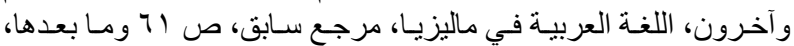

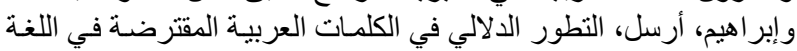

من الإسبانية، وكانت الإسبانية قد اقترضتهما من العربية. ومن الملحوظ أن الكلمة المقترضة تعامل معاملة الكلمة الأصلية، وتخضع لما تخضع له من لهن قواعد صوتية وصرفية ونحوية، ولهذا يصيبها أحيانًا كثيرًا من التحريف الذي يبعدها قليلاً أو كثيرًا عن وصناء أصلها (r). وبهذا يتضح أن الألفاظ المقترضة ينالها التحريف

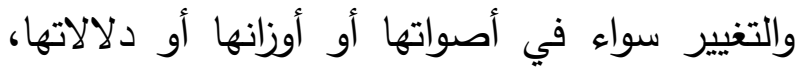
مما يبعدها قليلًا أو كثيرًا عن صورتها الأصلية. ويوضّح الجواليقي الكيفية التي تُخضع فيها اللغة

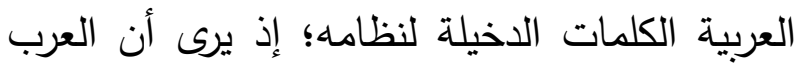

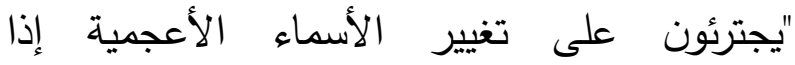
استعملوها، فيبللون الحروف التي ليست من حروفهم

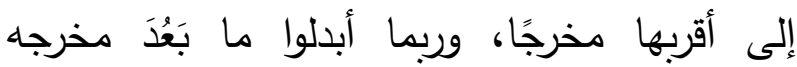
أيضًا.... وربما غيروا البناء من الكلام الفارسي إلى إلى الثيا أبنية العرب، وهذا التغيير يكون بإبدال حرف من حرف أو زيادة حرف أو نقصان حرف، أو إبدال

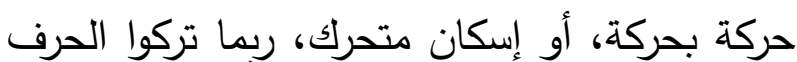

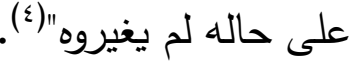
وما يتصل بالبحث هنا هو التطور الدلالي للألفاظ، فقد عَرَت علم الدلالة الحديث نظريات مختلفة

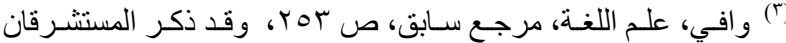

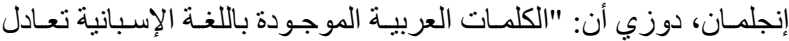

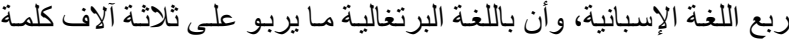

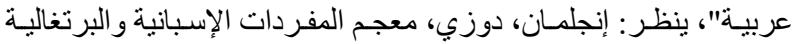

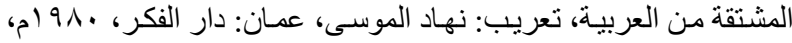

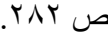

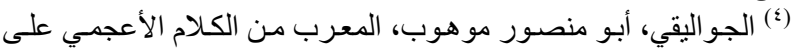

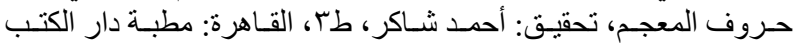

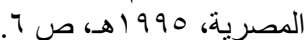


بطريقة مباشرة أو غير مباشرة، وبقدر طول مدى الاحتكالك وقوة أسبابه يزداد الأخذ والعطاء بين اللغتين، ومن عوامل انتقال المفردات هجرة الشعوب، وتجاور شعبين مختلفي اللغة، أو الاتصال السياسي،

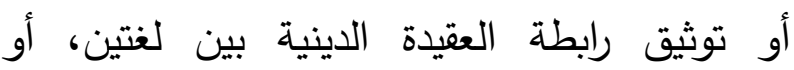

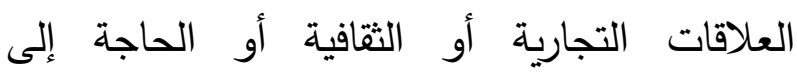

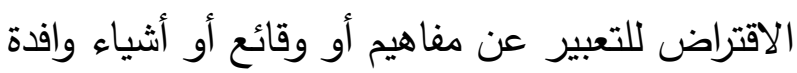
غريبة عن لغة أخرى، وقد حُِّّت أربعة معايير للتأكد من الحدوث الفعلي للاقتراض اللغوي، أولها: التقارب الصوتي، وثانيها: عدم انتماء اللغتين إلى لغة أصلية واحدة؛ لأن اللغتين اللتين لا تتتميان إلى الى

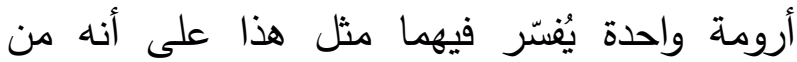
التوافق اللغوي؛ إذ إنه بسبب الأصول المشتركة يظل

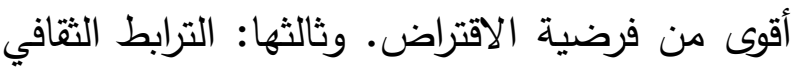
أو التجاري بين شعبين في أي حقبة زمنية، ورابعها: التقارب الدلالي بين الكلمتين(؛). والذي أراه أن النظائر المخادعة -سواء عدّت من لين قبيل الاقتراض اللغوي والتداخل بين اللغات التي لا تتتمي إلى أرومة واحدة أو من قبيل التوافق اللغوي بين اللغات التي تتنمي إلى أرومة واحدة-تظهر إنى بشكل واضح في اللغات المتقاربة سواء في الأرومة أو التأثر والاحتكاك المباشر وغير المباشر سواء كان جغرافيا أو ثقافيًا أو تجاريًا أو دينيًا في أي مجال تواصلي في حين تقلّ في اللغات المتباعدة في

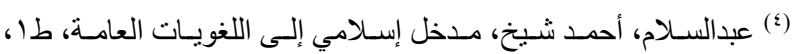

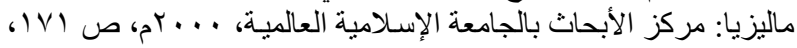

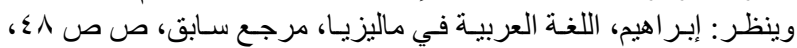

ومن أمثلة انحطاط الدلالة لفظ "غيرة" "ghairah" في الملايوية؛ إذ انحطت دلالته من معنى النخوة والذود عن العرض في العربية إلى معنى الثهوة الجنسية

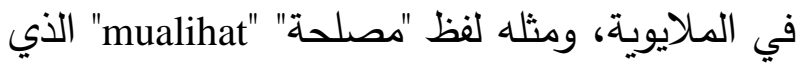
تحولت دلالته من معنى الخير الذي هو ضد الفساد إلى معنى الكيد والمكر • وهذا الأمر ينبغي مراعاته

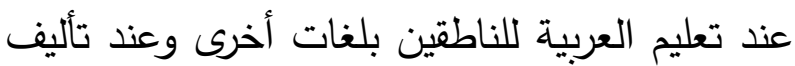
المناهج؛ لأن مثل هذه الألفاظ التي لها دلالات غير لهات إيجابية تؤثر على المتعلم وتضعه في حرج عند نطقها أو كتابتها؛ فمراعاة هذا الجانب له أهمية بالغة في تعليم اللغات سواء للطلاب أو الطالبات. ويقدّر بعض الباحثين نسبة الألفاظ العربية التي

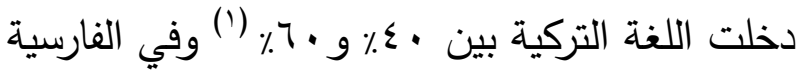

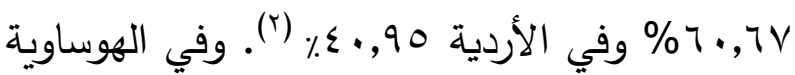

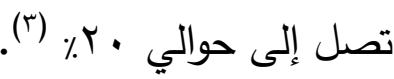
إذن لا بد لوقوع التبادل بين اللغات، المتمثل في

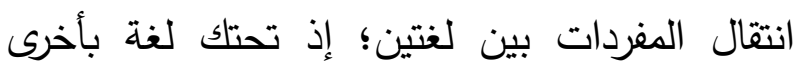

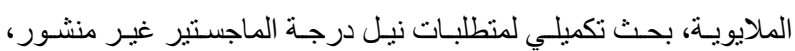

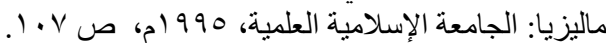

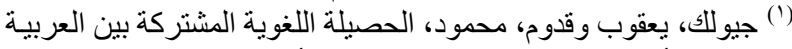

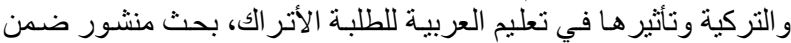

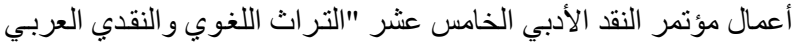

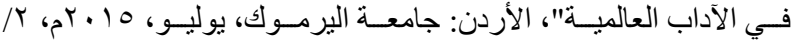

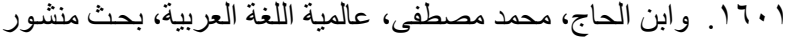

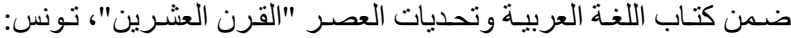

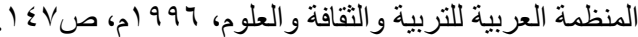

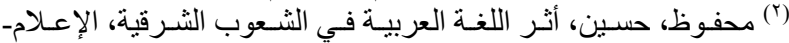

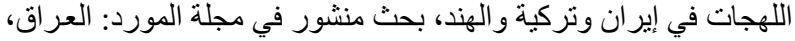

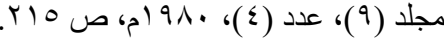

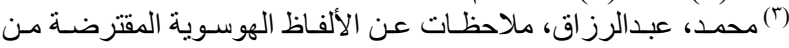

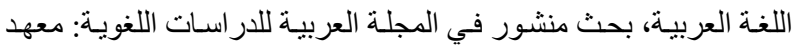

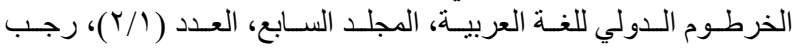

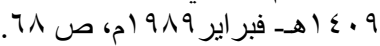


من الكلمات تدور في لغات العالم وأثرها تجاوز

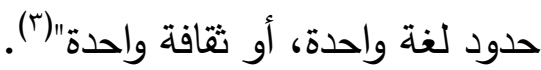
وهذا يقرر حقيقة أن التداخل اللغوي بين اللغات التي

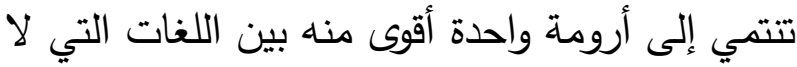
تتتمي إلى أرومة واحدة، ويتمثل التداخل اللغوي في

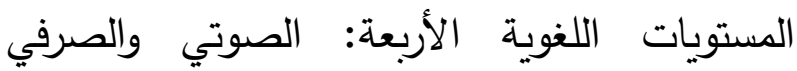
والنحوي والدلالي، فالنقل والتداخل يظهر بين الإنجليزية واللغات الأوروبية المتقاربة، ومنها الأمثلة الخاصة بالنظائر المخادعة التي أشار إليها الباحث الاثل سابقا بين الإنجليزية والفرنسية والإنجليزية والإسبانية؛ إذ تظهر أكثر شيوعًا من النقل والتداخل بين الإنجليزية والعربية أو العبرية أو الأردية مثنلً، في التئي حين سيكون شائعًا بين العربية والأردية، إذن يتضح التحديه

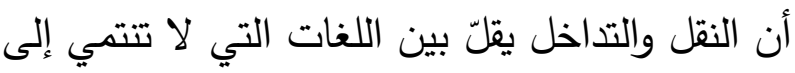

$$
\text { أرومة واحدة(£). }
$$

ثالثًا: النظائر المخادعة في الدأرس الغربي:

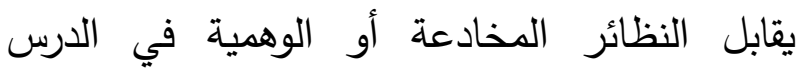
الغربي المصطلحات الآتية:

False cognates, False friends, Faux amis, Deceptive doubles, Paronyms ${ }^{\left({ }^{\circ}\right.}$.

وقد دُرِست على نطاق واسع في مجالات لغوية مختلفة: دراسات الترجمة أو تعليم اللغة أو المعجم

(") إسماعيل والأمين، التقابل اللغوي وتحليل الأخطساء، مرجع سـابق، ص

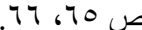
(؛) أبو عشنة، النظائر المخادعة في تعليم العربية للناطقين بغير هـا، مرجع

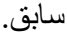

${ }^{\left({ }^{\circ}\right.}$ Look: Veisbergs, Andrejs, False Friends Dictionaries: A Tool for Translators or Learners or Both, University of Latvia, p.627
المؤثرات السابقة مع وجود ظاهرة الاقتراض بين

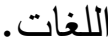
وقد اختلف العلماء والباحثون في أصل هذه الألفاظ، يقول السيوطي:" إذا وافق لفظ أعجمي لفظًا عربيًا في

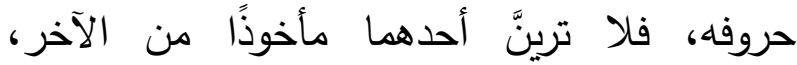
فإسحاق اسم النبي ليس من لفظ أسحقه الله إسحاقا أي: أبعده في شيء، ولا من باقي متصرفات هذه الكلمة، كالسحق وثوب سَحْق، ونخلة سَحُوق، وساحوق اسم موضع، ومكان سحيق، وكذا يعقوب اسم النبي ليس من اليعقوب اسم الطائر في شيء،

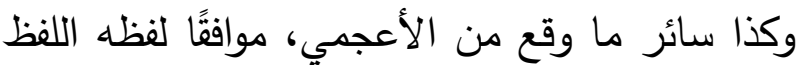

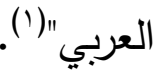

ويقول الثهابي: "إذا تشابه النطق في كلمتين لا يقوم

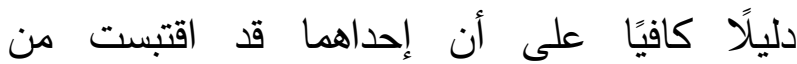

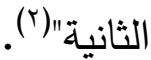
ويؤكد روبرت لادو، على وجود النظائر المخادعة في اللغات غير المتقاربة؛ إذ يقول: "هناك افتراض خاطئ بأن النظائر لا يمكن وجودها إلا في لغتين ترتبطان في النسب، كالإنجليزية والإسبانية، غير أن لهن هناك كثيرًا من النظائر توجد في الإنجليزية واليابانية، والإنجليزية والصينية، وفي عدد آخر من الإن اللغات التي لا تربطها علاقة، كما أن هنالك كثيراً

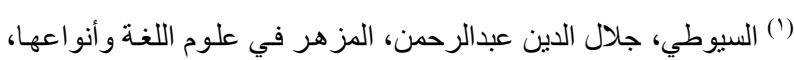

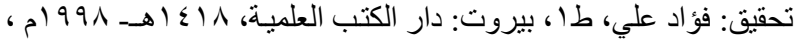
$r+r / 1$

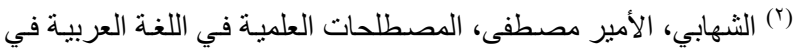

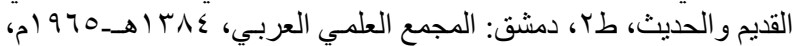


Postigo Pinazo, E. (2007) Diccionario de Falsos Amigos: Inglés-Español .Madrid: Ediciones Verba.

ع. قاموس النظائر المخادعة، لهيل روبرت. لندن:

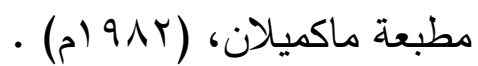

Hill, R. (1982) A dictionary of false friends. London: Macmillan Press.

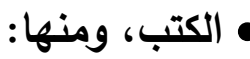

ا . كتاب بعنوان: النظائر المخادعة في الترجمة: معايير الدراسة والتصنيف. لألفاريز لوغريس، فيغو: جامعة فيجو، (99V (م). Álvarez Lugrís, A. (1997) Os Falsos Amigos da Traducción: Criterios de Estudio e Clasificación. Vigo: Universidade de Vigo.

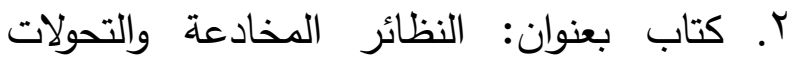

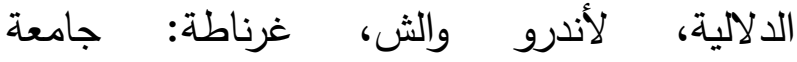

$$
\text { غرناطة، (0. - م. م). }
$$

Walsh, Andrew, (2005) False Friends and Semantic Shifts, Editorial Universidad de Granada.

ץ. كتاب الدلالات والتداولية للنظائر المخادعة،

لتشاميزو دومينغويز بيدرو، لندن: نيويورك-

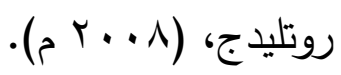

Pedro J. Chamizo-Domínguez, (2008) Semantics and Pragmatics of False Friends، London: New York- Routledge.

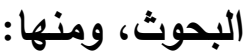

ا. بحث بعنوان: النظائر المخادعة في الكلام والكتابة: دراسة على الجسد في النظائر المخادعة الإنجليزية في إنتاج الطلاب الإسبان.
اللغوي أو اللغويات التقابلية في جميع أنحاء

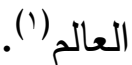
والهدف من عرض الدراسات الغربية التي تتاولت النظائر المخادعة هو بيان الاهتمام بها، وإدراك أثرها على المتعلمين، وأهمية الوقوف عندها. يشها على ذلك وفرتها، وهذا يؤكد على أنها تمثل صعوبات على متعلّم اللغة سواء كانت أجنبية أو ثانية، وأنها تستحق التأمل والبحث، ولذا أفردتها بنقطة مستقلة وفصلتها عن الدراسات السابقة. ويمكن عرض بعضها على النحو الآتي: القواميس، ومنها:

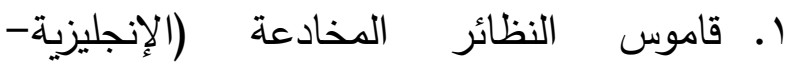
الإسبانية)، لبرادو مارسيال، مدريد:غريدوس، $\cdot(r+\cdots)$

Prado, M. (2001) Diccionario de Falsos Amigos: Inglés-Español. Madrid: Gredos, D.L.

r. قاموس مصطلحات خادعة "النظائر المخادعة" (إنجليزي - إسباني_ إنجليزي)، لميغيل كانسا، مدريد: إديتوريال الحمراء. (9^v (م). Cuenca, M.(1987) Diccionario de Términos Equívocos ("Falsos Amigos") Inglés-EspañolInglés. Madrid: Editorial Alhambra.

r. قاموس النظائر المخادعة: إنجليزي- إسباني، لإنكارناسيون بوستيغو بينازو، مدريد: إديسيونس

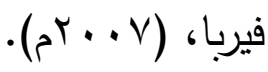

The Problem of False Friends in Learner Language, (') op cit, p2 
False Friends: their Origin and Semantics in Some Selected Languages ${ }^{(r)}$.

يهدف البحث إلى التحقيق في الهياكل الدلالية (التصويرية) التي تكمن وراء النظائر المخادعة، وخاصة على المستوى الدلالي، في مختلف اللغات الأوروبية: (الإسبانية، والفية والألمانية، والإنجليزية)؛ إذ إنها تتشابه في الشكل وتختلف في المعنى، ويمكن اعتبارها معادلات لغوية للكلمات متعددة اللغات بلغة طبيعية واحدة. ويمكن أن تقوم الروابط بين معانيها في لغات مختلفة على الاستعارة، والكناية والتلميح، وكذلك على التخصيص والتعميم. فالنظائر المخادعة هي الآثار الدلالية دن استخدام اللغة التداولية على در الزمن. ولها آثار مهمة على الترجمة الفورية والترجمة اللغوية؛ إذ يكون الوعي بالنظائر المخادعة مهما ومعرفة بعض الإستراتيجيات العملية، التي تساعد على تجنب سوء الفهم أو عدم التساؤل. كما تضيف دراسة الصلات التفسيرية الكامنة بين النظائر المخادعة بعدا جديدا

$$
\text { إلى الدلالات المعرفية. }
$$

ع. بحث بعنوان: النظائر المخادعة في القواميس ثنائية اللغة" نظائر مخادعة" المعجمات في بولندا

$$
\text { الدولية. }
$$

False Friends in Dictionaries. Bilingual False Cognates lexicography in Poland International $^{(1)}$.

Pedro J. at all, Nottingham NG7 2RD, UK Received (")

22 September 2000; received in revised form 14 January 2002; accepted 15 January 2002. Journal of مناح على Pragmatics 34 (2002) 1833-1849. الموقع: المسلى
Faux amis in Speech and Writing: a CorpusBased Study of English False Friends in the Production of Spanish Students (').

وكثف هذا البحث من خلال التحليل أن المتعلمين أقلّ خطأ في استعمال النظائر المخادعة في الكتابة في حين تظهر بصورة أكثر في الكلام، ويظهر أيضًا أن بعض النظائر المخادعة في الإنجليزية صعبة بشكل خاص على المتعلمين. Y. بحث بعنوان: "مشكلة النظائر المخادعة في لغة

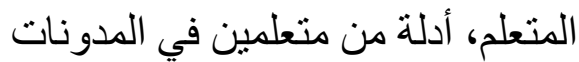
The Problem of False Friends in Learner Language Evidence from Tow Learner Corpora, Santiago University Learner of English $\left.{ }^{(}{ }^{(}\right)$.

وهدف البحث إلى الإجابة عن الأسئلة الآتية: هل يواجه الطلاب صعوبات حقيقية مع النظائر المخادعة؟ وما نوع المشكلات التي يمكن تحديدها من البيانات الموجودة في المدونات؟ وهل هناك أي حلول ممكنة لهذه المشكلات؟ وخلص البحث إلى أن النظائر المخادعة تؤدي إلى إشكالات متعددة r. بحث بعنوان: النظائر المخادعة: الأصل والدلالة في بعض اللغات المختارة.

Look: María Luisa Roca-Varela. (2014), Faux amis in (') Speech and Writing: a Corpus-Based Study of English False Friends in the Production of Spanish Students Recent Advances in Corpus Linguistics,VOL.78, pp 293-307, DOI: 10.1163/9789401211130_014

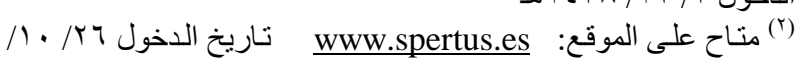
ه $\leqslant$ ا 
على نظائر مخادعة بين أصناف مختلفة من اللغة نفسها، كما هو الحال مع الإنجليزية البريطانية

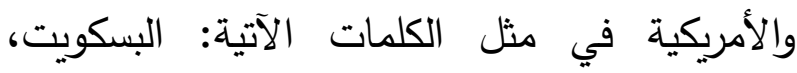
والخل، والسراويل، والمطاط، التي تستخدم على حد سواء في اللغة الإنجليزية البريطانية والأمريكية ولكن معانيها تختلف تماما. ويقوم البحث بتحليل الاختلافات الدلالية من هذه العناصر في كل الأصناف لدعم الحجج مع البيانات المستخرجة من من لاهن قاموسين رئيسين على الإنترنت (قاموس كامبردج) و (قاموس أكسفورد) ومن شركتين، هما: ( كوربوس الإنربن

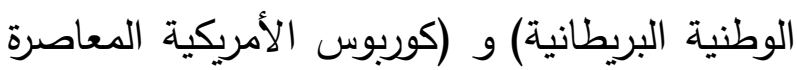
الإنجليزية ). ويعود وجود النظائر المخادعة بين الإنجليزية البريطانية والأمريكية إلى العوامل الجغرافية، والخصوصيات الثقافية، والتطورات المنفصلة للغة في كلتا الدولتين التي تلعب دورا في

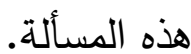

وغالبا ما تستعمل مجازيا النظائر المخادعة في مجال اللغويات؛ لتشير إلى وجود بعض العناصر المعجمية في اللغتين؛ لأنه يبدو أنها سهلة الفهر وجهي والتعلم لأول وهلة، ولكن ليس الأمر كذلك لغير الناطقين باللغة؛ لأن شكلها ليس مؤشرا على معناها

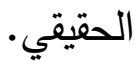

7. بحث بعنوان: التعليم والتعلم " النظائر المخادعة": استعراض بعض المراجع المفيدة.
يقدم هذا البحث النظائر المخادعة ثنائية اللغة في معجم بولندا في السنوات الخمس عشرة الماضية. وقد تم إنتاج قواميس من النظائر المخادعة بأعداد كبيرة لوضع البحوث النظرية الخاصة بالتكافؤ المعجمي للنظائر المخادعة في الممارسة، فضلا عن الميل الملحوظ لإنتاج قواميس متخصصة، وكأداة عملية مفيدة في تعليم اللغة الأجنبية والتعلم، والترجمة التحريرية والترجمة الشفوية يتم تحليل عدد من القواميس التي تكثف عن اختلافات في فهم هذه الظاهرة المعجية ويحاول البحث تغطية جميع جوانب وصف النظائر المخادعة في المواد التي تم تحليلها ويسلط الضوء على المشكلات الرئيسة المتعلقة بعرض دقيق وشامل للنظائر المخادعة في المعجمات من حيث النطق والنحو والدلالات. ه. بحث بعنوان: النظائر المخادعة داخل اللغة: الإنجليزية البريطانية والأمريكية دليل على ذلك. Intralingual False Friends: British English and American English As a Case in Point ${ }^{\left({ }^{(}\right)}$. يشير البحث إلى أنه عادة ما ينظر إلى "النظائر المخادعة" على أنها تداخل لغوي ومن الظواهر التي التي

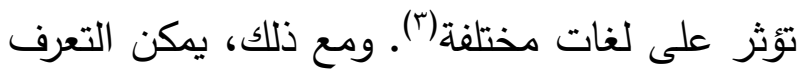

Szpila, G. 2006. Journal of Lexicography 19/ 1, (1) ينظر 73-97, https://doi.org/10.1093/ijl/eci041

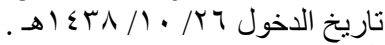
University of Santiago de Compostela, Available at: (T) $M^{a}$ Luisa Roca-Varela, 2006,

ttps://www.srcf.ucam.org/camling/proceedings/rocavare

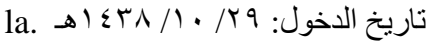

Hill 1982; Prado !Derocquigny 1928 \& Koessler ${ }^{\left({ }^{(}\right)}$ Look: Nerlich 2002; \& 2001; Chamizo Domínguez (Malkiel 2005 \& Shlesinger) 
عرض النظائر المخادعة. وهذه المشكلة أيضا تتعلق

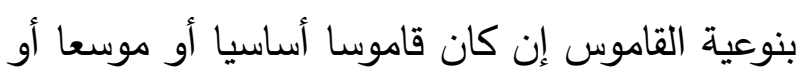

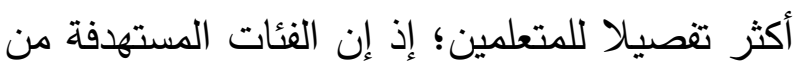
المستخدمين لهذه القواميس تحتاج إلى عرضها بشكل محدد. ويعرض البحث طموحات المتعلمين والمترجمين من وراء استخدام قواميس النظائر المخادعة وفائدتها. واستعراض الجوانب العلمية لاستخدامها وأهميتها في القاموس، ويبدو أن سبب ولبعان إعادة الاهتمام في هذا المجال يعود بصفة رئيسة إلى لى لئس مشاكل التعلم المتعلقة بالمعاني. وقد تمت الاستفادة

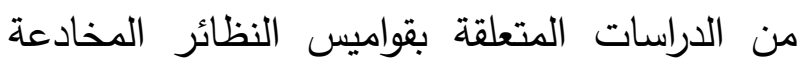
بنجاح في التعليم، كما تجرى محاولات لإنشاء قواعد بيانات بهذا الخصوص، وهذه القواميس هي بمثابة أدوات مخصصة للمتعلمين. ^. بحث بعنوان: النظائر المخادعة: منظور تاريخي وحاضر الآثار المترتبة على الاكتساب المعجمي. False Friends: A Historical Perspective and Present Implications for Lexical Acquisition ${ }^{(')}$.

يشير البحث إلى أن النظائر المخادعة توجد في جميع اللهجات الأوروبية، نتيجة الاقتراض من البطن مصدر واحد هو اللاتينية، عندما تأتي اللغات متصلة كما يحدث في اكتساب اللغة الثانية، وهذه النظائر المخادعة تشكّل مصدرًا للتداخل المعجمي في جميع مستويات اللغة.

O'Neill, Maria and Catalá, Montse Universitat de (') Lleida, Available at:

http://www.raco.cat/index.php/bells/article/download/10 2791/149196
Teaching and Learning "False Friends" A Review of Some Useful Resources ${ }^{(1)}$. يقدّم البحث النظائر المخادعة باعتبارها مفردات في لغتين متشابهتين في الشكل ولكنهما مختلفتان في المعنى، وهي مهمة في التعلّم؛ لأنها تؤدي إلى لى فئس

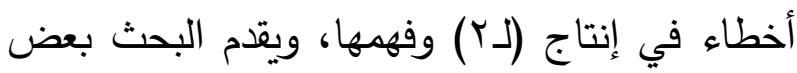
الأدوات المفيدة (القواميس، الموارد على الانترنت،

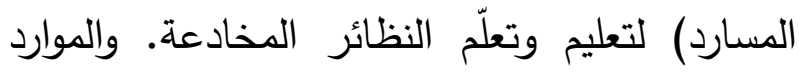
المعروضة في البحث تسمح باكتشاف تعقيد ظاهرة النظائر المخادعة، وخلص البحث إلى أن وجود هذه المواد سيساعد متعلمي اللغة في لفهم هذه الكلمات وتعلمها بطريقة ناجحة. V. بحث بعنوان: قواميس النظائر المخادعة: أداة للمترجمين أو المتعلمين أو كليهما. False Friends Dictionaries: A Tool for Translators or Learners or Both ${ }^{(\Upsilon)}$.

يشير البحث إلى أن قواميس النظائر المخادعة هو مجال معجم ثنائي اللغة، يتناول بشكل رئيس

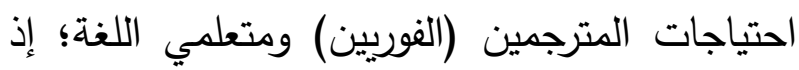
إن تنوّع قواميس النظائر المخادعة ثنائية اللغة -

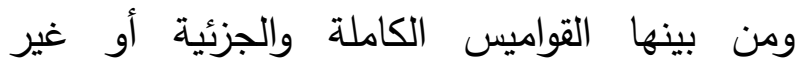

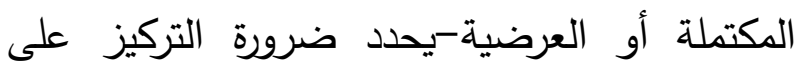
النظائر المخادعة المحددة بالنسبة لفئات معيّنة من مستخدمي اللغة إذا كان الهدف من تلك القواميس

$\mathrm{M}^{\mathrm{a}}$ Luisa Roca Varela, University of Santiago de (1) Compostela. Encuentro 20, 2011, ISSN 1989-0796, pp. 80-87

https://www.tib.eu/en/search/id/BLCP\%3ACN0176050 Andrejs, Op cit, Available at: $\underline{82 /}$

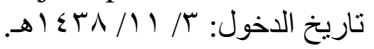


في حين أنها تعني "هدية" في الإنجليزية"(؛)، وكذلك بين الهولندية والإنجليزية في كلمة (consequent) التي تعني "متسق"، وفي الإنجليزية تعني "يترتب على ذلك (0).

رابعا: أثر النظائر المخادعة في تعليم اللفة

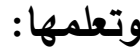

تشكّل ظاهرة النظائر المخادعة في اللغات تأثيرا على المتعلمين وينبغي الاهتمام بها انطلاقًا من أن متعلم اللغة العربية مثلاً لا يبدأ من فراغ، وإنما يبدأ بنقل ما في لغته إلى اللغة المتعلمة سواء على مستوى الأصوات أو الصرف أو النحو أو الدلالة، لئه وخاصة إذا لاحظ التشابه بينهما أو وجد صعوبة فيما يبحث عنه في اللغة المتعلمة، ومن الطبيعي أن يجد

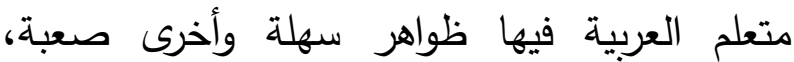
انطلاقا من أن المتعلم الناجح يفترض ابتداءً أن اللغة العربية التي يتعلمها تختلف عن لغته الأم، وأن عليه أن يبذل جها لاكتسابها، لكنه في النهاية مجبول على ملاحظة أن ثمة ظواهر تشبه أشياء في

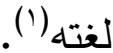

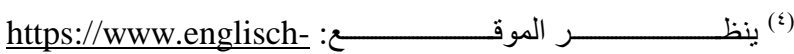
hilfen.de/en/words/false friends.htm ${ }^{(\circ)}$ Look: Burkholder, Michèle. Les Faux-Amis: Investigating Lexico-Semantic Ambiguity Across Two Languages, University of Ottawa, Proceedings of the 2015 Annual Conference of the Canadian Linguistic Association. At: cla-acl.ca/wpcontent/uploads/Burkholder.pdf

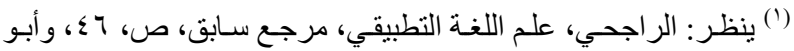
عمشة، النظائر المخادعة في تعليم العربية للناطقين بغير ها، مرجع سابق.
وغير هذه الدراسات، فإن هنالك العديد من الدراسات الأخرى التي تتاولت الموضوع نفسه(؟). ومن الماحظ حول هذه الدراسات أنها درست النظائر المخادعة في فصيلة اللغات الهندوأوربية، سواء اللغات الجرمانية التي منها: الألمانية والهولندية والإنجليزية أو اللغات الرومانية (اللاتينية)، ومنها: الفرنسية، والإسبانية، والبرتغالية. وهذا يؤيد القول الإنيان بوجود هذه النظائر في اللغات المتقاربة بشكل

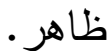

ومن أمثلة اثتراك النظائر المخادعة في الدال واختلافها في المدلول، ما يفيده الفعل الفرنسي

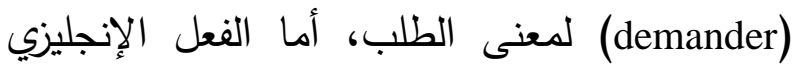
فيعني فرضا وأمرا، فالدارس الفرنسي الإنيلي (to demand) قد يخطئ إن استعطل الفعل (demander) في معنى وكذلك الأمر لكلمة (to demand) ترد في الفرنسية والإنبانية بمعنى "حساس" وتفيد معنى "الحكيم والعاقل" في الإنجليزية؛ فيهذا تفيد التيد النظائر المخادعة معاني متقابلة تماما، وتربك عندئذ النجائن الدارس عند استخدامه لهاب("). ومن أمثلة النظائر المخادعة بين الألمانية والإنجليزية كلمة (gift)؛ إذ تعني "السم" في الألمانية

${ }^{\left({ }^{(}\right)}$Look For Example: M. Martha, Lengeling, Universidad De Guanajuato, True Friends and False Friends, Volume 19, Number 2, Convention Issue 1995, NYS Statewide Language RBERN - False Cognates: English/ Spanish, 2015, The University of The State of New York/ Albany, NY 12234.

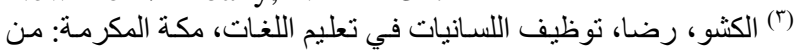

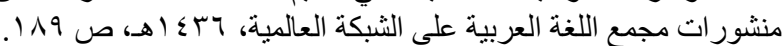


الأجنبية('). وبهذا يظهر أن من المشكلات التي

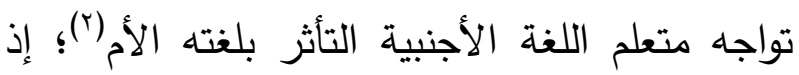
"إن اكتساب لغة ثانية يتحدد بصورة كبيرة بفعل الأنماط الصوتية واللغوية الخاصة باللغة الأولى التي تم تعليمها، فالتراكيب والصيخ اللغوية التي تشبه تلك الموجودة في اللغة الأصلية يتم تمثلها وتعلمها بسهولة، وتسمى هذه العملية بالنقل الإيجابي، أما الصيخ والتراكيب المختلفة فإنها تشكّل عقبة في سبيل تعلم اللغة الثانية أو الأجنبية، وتسبب حدوث الأخطاء اللغوية نتيجة النقل السلبي"(־َ). ولهذا نجد أن"التّّخُّل بين اللغات المتقاربة أقوى منه بين اللغات غير المتقاربة، وهناك أمثلة كثيرة لهذا التّدخُل على مستويات الصوت والكلمة والجملة والمعجم، تم رصدها بين اللغات الأوروبية المتقاربة كالإنجليزية والألمانية مثلا، منها الأمثلة الخاصة بالنظائر المخادعة... وهي لا توجد عادة بين اللغات المتباعدة، وكثير من هذه المشكلات لا ترصد مثلا بين متعلمي الإنجليزية من أبناء العربية"(£). فمن الطبعي أنه عندما نتعلم لغة أجنبية نميل إلى الى نقل نظام لغتنا بكامله إلى اللغة الأجنبية ويتم هذا

Lado, R. (1957), Linguistics Across Culture: Applied (') Linguistics for Language Teachers, University of Michigan press: Ann Arbor, p.75.

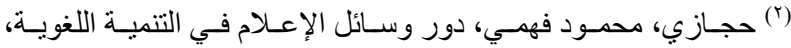

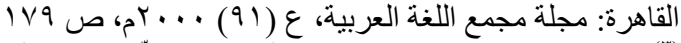

يقول الجرجاني:" فكل من عرف أوضاع لغة من

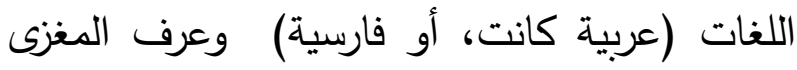
من كل لفظة، ثم ساعده اللسان على النطق بها، وعلى تأدية أجراسها وحروفها، فهو بين في تلك لكاعن اللغات، كامل الأداة، بالغ من البيان المبلغ الذي لا لا مزيد عليه، منته إلى الغاية التي لا مذهب بعدها"(؟). ويعزو أونيل (O, Neill) المشكلات الرئيسة التي تواجه دارسي اللغات الأجنبية إلى الاختلاف بين لغة

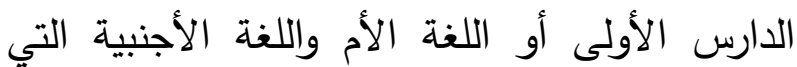
يدرسها، ويتتاول هذه الاختلافات من أربعة أوجه (r): ا ـ النظام الوراثي (genetic system). r. النظام اللغوي التركيبي (syntactic system) r. اكتساب اللغة (language acquisition) ـ ـ مقاومة اللغة (language resistance) وتقوم نظرية التقابل اللغوي على ما توصل إليه روبرت لادو من أن تعلّم اللغات الأجنبية يتأثر كثيرا

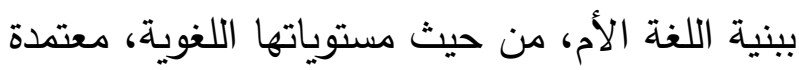
في ذلك على ما يعرف بالنقل الإيجابي( سهولة تعلم

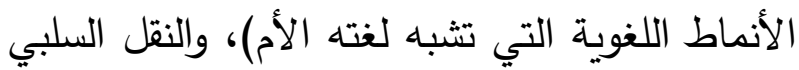

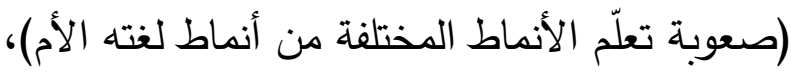
وهي في ذلك تمثل صعوبات لمتعلم اللغة

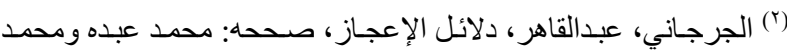

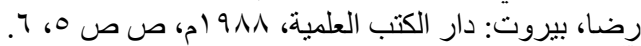
O, Neill, R, (1998), Language Acquisition and CLT. Retrieved June 21, 2010 from: http://www.btinternet.com/ $\sim$ ted . power/ es 10412.html.

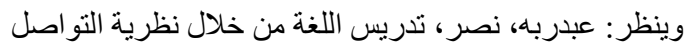

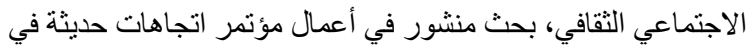

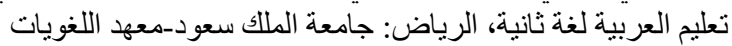

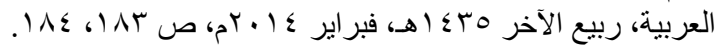


أصول جرمانية، على حين أن اللغة الصينية أيسر للفيتناميين والتايلنديين، ولكن لا توجد لغة صعبة أو سهلة في ذاتها"(؟). وينبغي مراعاة النظائر المخادعة على مستوى المفردات عند تعليم اللغة العربية وتعلّمها، وكيفية تصنيف مثل تلك المفردات؛ إذ إنها قد تشكل صعوبة على المتعلم، وقد ذكر روبرت لادو أنه من المناسب

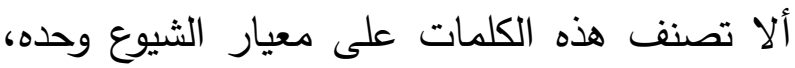
فيقول:" وتلك الكلمات المتشابهة في الثكل والمختلفة في المعنى أو النظائر الخادعة -كما سميناهاتشكل مجموعة خاصة على درجة عالية جدا من الصعوبة، وسوف نشير إليها بكلمة (صعبة) ومن المناسب ألا تصنف هذه الكلمات بناء على معيار الشيوع وحده نسبة؛ لأن تثابهها في الثكل لكلمات في اللغة الأجنبية يرفع من درجة شيوعها واستعمال

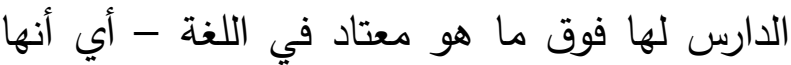
بمعنى آخر - أكثر أهمية مما يشير إليه تقرير شيوعها، وهي مواطن أكيدة للخطأ"(؟). ويقترح روبرت لادو، عدة خطوات لهقارنة المفردات؛ إذ لابد أن تشتمل المقارنة بين كلمات اللغتين (ثم) بين المجموعات وأنماط الكلمات) مجالات الصيغ لانين

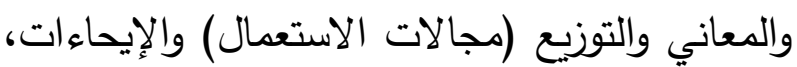
فالخطوة الأولى: مقارنة الثكل (الصيغة)؛ إذ من خلال تلك المقارنة نحصل على نوعين من الكلمات:

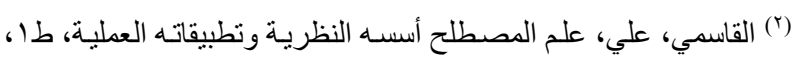

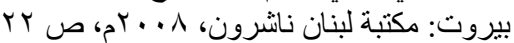

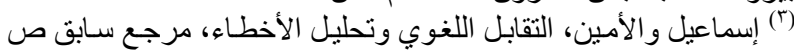

النقل بطريقة لا شعورية؛ إذ لا ينتبه المتعلم إلى ذلك ما لم يوجه نظره إلى الاختلاف بين لغته

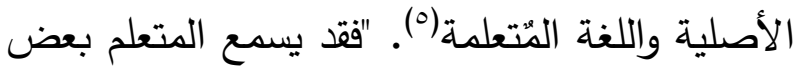
الأصوات فيظن أنها أصوات تشبه أصواتا في لغته الأم، وهي في واقع الأمر خلاف ذلك"("). وهذا ما يعبّر عنه بالنظائر المخادعة التي يكون بينها تشابه يوهم المتعلم أنها مثل الأصوات أو لوات لئر الكلمات أو التراكيب التي في لغته الأم، وهي مخادعة للمتعلم في الوقت نفسه باختلافها عما في لي لفي

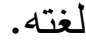
ويشير عبده الراجحي" إلى أن التشابه بين لغتين لا

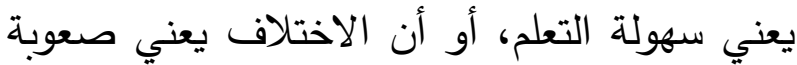

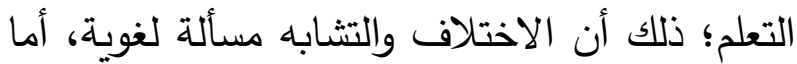

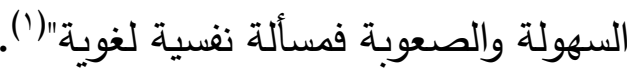
ويعلّق عليّ القاسمي عند حديثه عن لغات صعبة وأخرى، بقوله:" الصعوبة الممكنة تنتج من تأثير اللغة الأم السلبي على اللغة الأجنبية التي نتعلمها، وهذا ما يصطلح عليه بالتداخل اللغوي، فكلما ازدادت الفروق بين اللغتين ازدادت الصعوبة التي يواجهها الفرد في تعلّم اللغة الثانية، وهكذا يصح القول: بأن الصعوبة تتناسب عكسيًا مع التقارب بين

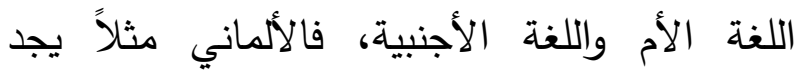
الإنكليزية أسهل من الصينية؛ لأن الإنكليزية ذات صن (إسماعيل والأمين، الثقابل اللغوي وتحليل الأخطاء، مرجع سابق، ص .

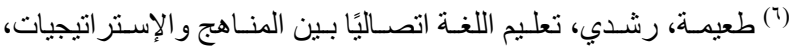

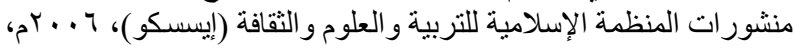
ص م 1.. (') الر اجحي، علم اللغة التطبيقي، مرجع سابق، ص V؟ . 
المخادع دون تصحيح في الفصل الدراسي أحادي

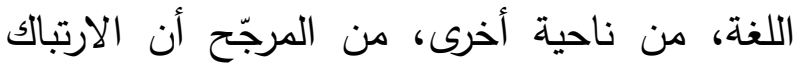

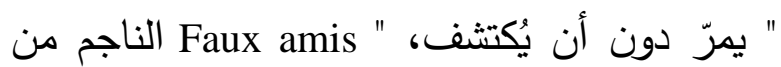
"La

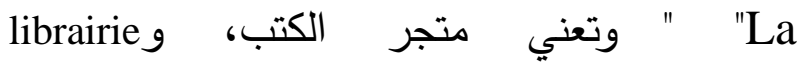
تعني المكتبة، وكان يقصد أن يقول: "bibliothèque" وتعبي إنهم أمضوا ساعة في متجر الكتب، سيقول: J'ai passé une heure dans la librairie.

ولكن هذا منطوق نحوي وذو معنى، فالمعلم قد لا يدرك أي شيء خاطئ، كما أن المعنى الصحيح

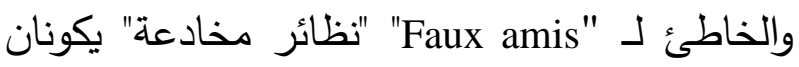
مرتبطين ببعضهما، وتصحيح الترجمة يعدّ وسيلة فعالة بشكل خاص للتأكد من أن مثل سوء هذا الفهم سيظهر • وهذا لا ينطبق فقط على المستوى المعجمي ولكن على المستوى النحوي والتداولي أيضا. ففي الفرنسية "Passe compose" على سبيل المثال "الماضي المركب" يكافئ نحويا في الإنجليزية المضارع التام، ولكن استخدامه ومعناه يختلفان في بعض الأحيان؛ وقد تكون صيغة الأمر الروسية والإنجليزية متكافئتين نحويًا ولكن تختلف قوتهما الذاتية"(").

ويظهر أيضا أثر النظائر المخادعة في الترجمة بين اللغات؛ إذ قد يتم الخلط بين دلالات المفردات

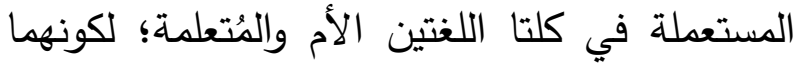
تلفظان بالطريقة عينها لكن بمعانٍ مختلفة، فيغفل

Cook, Opcit, pp. 137,138. (r)
ب. أ. الكلمات المختلفة في الثكل. فالكلمات المتشابهة في الثكل يعاد تصنيفها في أنماط تناظر بين اللغتين الأصلية والأجنبية، وتلك الكلمات المختلفة في الثكل يعاد النظر فيها مرة

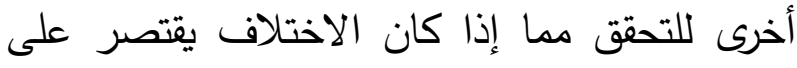
الثكل فقط أم أنه يتعدى ذلك إلى البنية، ثم تأتي الخطوة الثانية: مقارنة المعنى؛ إذ ننظر إلى الكلمات المتشابهة ونقابل المعاني المختارة في القائمة بمعاني الكلمات المتشابهة في لغة الدارس، فإذا كانت تلك

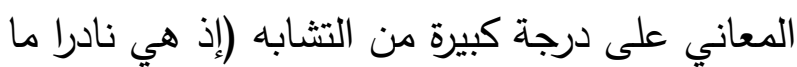
تتطابق بصورة تامة) نعتبرها نظائر، أما إذا كان الاختلاف بينها واضحًا فيتم تصنيفها باعتبارها نظائر خادعة "deceptive cognates" وتعدّ صعبة

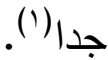

وكما أن للنظائر المخادعة أثرا في العملية التعليمية

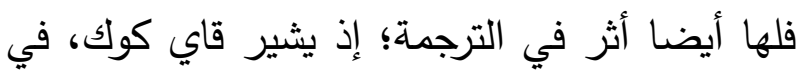
هذا السياق إلى أن هناك حالات قد يعتّد المتعلمون فيها أنهم يدركون شيئا، ولكنهم مخطئون. فعلى الى هلى Faux amis " المستوى المعجمي فإن التعبير التقليدي:" "نظائر مخادعة" وهي الكلمة التي تبدو هي نفسها

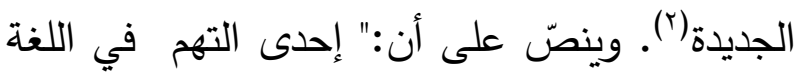
الرئيسة ضد الترجمة أنها تعزز الثعور بالنظير

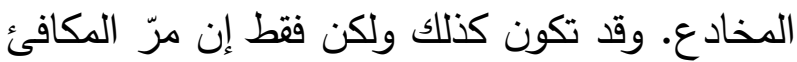

(1) إبماعيل و الأمين، التقابل اللغوي وتحليل الأخطاء، مرجع سابق ، ص

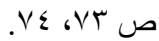
${ }^{(\Gamma)}$ Cook, Guy, (2015), Translation in LanguageTeaching, Oxford: Oxford University Press, p.137 
الناطقين باللغات المحددة، ولا يهدف إلى قياس الثروة اللغوية عند المتعلمين. مواصفات الاختبار والمحتوى:

الاختبار موضوعي: "اختيار من متعدد" ويقع في صفحتين الأولى فيها بيانات الطالب الديموغرافية (الاسم/ الجنس/ العمر) والجهة التعليمية التي ينتسب إليها، وتعليمات الاختبار، والأخرى تشتمل على سؤال واحد ونصـه: ضع دائرة حول معنى الكلمة الصحيح في اللغة العربية للكلمات التي تحتها خط، وهو عبارة عن عشر فقرات توضع الكلمة المستهدفة في جملة تحتها خط ولونها غامق "بنط عريض" تمييزا لها، ثم تحتها أربعة خيارات (أ، ب، ج، د). تبدأ الفقرة بجملة بسيطة تكون فيها الكلمة المراد اختيار معناها الصحيح وتحتها خط وتم تمييزها بلون داكن، ثم يأتي تحت الجملة "الساق" أربعة خيارات (أ، ب، ج، د) أحدها المعنى الصحيح، والثاني النظير المخادع في اللغة المحددة في الاختبار ومشتتان آخران وجاء ترتيب الخيارات وفقا للترتيب الهجائي للحروف العربية. واختيرت هذه المفردات، وكتبت الجمل على ضوء

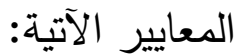

ا ـ شيوع المفردات في اللغات المستهدفة وتداولها، واتضح ذلك من خلال تحكيم الأساتذة ممن لغتهم الأم إحدى هذه اللغات المستهدفة، وإفادة أساتذة يعلّمون تلك اللغات بشيوع هذه المفردات، وكذلك من
المترجم أثثاء الترجمة وينظم النسق في الجملة كأنها جارية في اللغة المصدر، فيؤدي ذلك إلى خطأ دلالي، فمثلا: كلمة "التفات" بالعربية تعني الميل إلى اتجاه ما، في حين تستخدم في التركية باللفظ نفسها "iltifat" المحور الثاني: الإطار التطبيقي (الميداني) • إجراءات التطبيق الميداني: يعرض البحث في هذا الجزء وصفًا للأدوات، والعينة، وإجراءات التطبيق، ونتائج البحث وذلك على

$$
\begin{aligned}
& \text { النحو الآتي: } \\
& \text { أولا: أدوات البحث: } \\
& \text { أ. الأداة الأولى: }
\end{aligned}
$$

إعداد اختبار • موضوعي لقياس أثر النظائر المخادعة في اكتساب معاني المفردات لدى متعلمي اللغة العربية الناطقين باللغات المحددة؛ إذ تم اختيار عشر مفردات في كل لغة لها نظائر مخادعة في اللغة العربية؛ ووضع في كل لغة اختبار مستقل خاص بالمفردات التي بينها تتاظر مع العربية، مع توحيد صياغة الأسئلة وطريقتها واختلاف الجمل

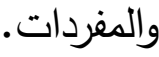

\section{أهداف الاختبار :}

يهدف الاختبار إلى قياس أثر النظائر المخادعة في اكتساب معاني المفردات لدى متعلمي اللغة العربية

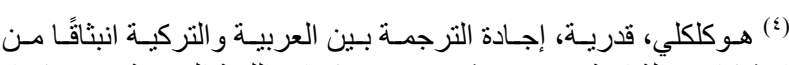

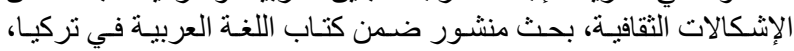

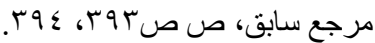
• الملحق (r) ويمكن الاطلاع على نماذج الأسئلة من خلال التو اصل مع الإنى الباحث على البريد الإلكتروني: Salhogory@kau.edu.sa 
خلال الرجوع إلى المعمات اللغوية الخاصة بكل وأسفرت هذه الخطوة عن وضوح تعليمات الاختبار وقياس المفردات للعنصر اللغوي الذي هدف الاختبار لقياسه، كما أسفرت عن بعض التعديلات في صياغة الأسئلة واستبدال بعض المضات المغردات بغيرها.

\section{• تصحيح الاختبار}

قمتُ بتصحيح الاختبار وتحليل النتائج ورصدها؛ إذ إذبار وضعت جدولا لنتائج الطلاب والطالبات المستجيبين للاختبار في كل لغة من اللغات الخمس، ثم جدولا

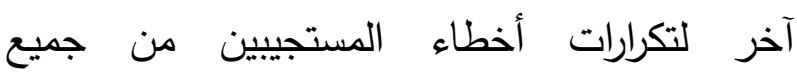

$$
\text { ب.ائليات الثانية: والنسب المئوية. }
$$

عُمِلت استمارة تحكيم لنماذج الاختبار ؛ وقد تكونت من صفحة الغلاف وفيها عنوان البحث وبيانات الباحث ثم صفحة تتضمن خطابا موجها للأساتذة المحكمين يوضح المهام المطلوبة دنهم، ثم استمارة التحكيم واشتملت على معلومات المحكم (الاسمالدرجة العلمية- التخصص- جهة العمل) وبنود

$$
\text { القائمة وهي: }
$$

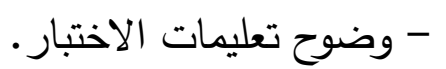

- مناسبة الاختبار لمستوى الدارسين في المستوى لإنيان

- وضوح مفردات الأسئلة وسهولتها. - دقة الصياغة العلمية للأسئلة.

• الملحق (1) و يمكن الاطلاع على استمارة التحكيم من خلال التو اصل مع الباحث على البريد الإلكتروني: Kalhogory @ kau.edu.sa

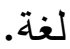
r. وضعت المفردات في سياقات لتحديد معناها بدقة من خلال السياق الذي وردت فيه؛ لأن بعض المفردات تحتمل أكثر من معنى؛ فيكون السياق هو

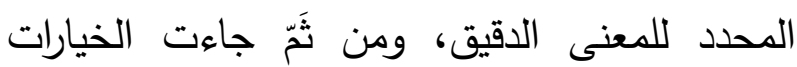
موافقة للمفردات في السياق. r. ب بساطة الجمل وقصرها. ع ـ مناسبتها لمستوى المتعلمين. 0. تناسب الخيارات من حيث عدد المفردات وتركيبها، والتعريف والتتكير، والإعراب.

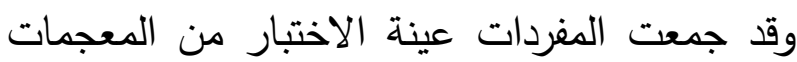
اللغوية في كل لغة ومن الدراسات والبحوث المتعلقة بالموضوع. • صياغة الاختبار: صيغت الأسئلة بطريقة

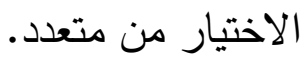
• تعليمات الاختبار: صغتُ تعليمات الاختبار بأسلوب واضح، مؤكدا على ضرورة كتابة البيانات الشخصية للطلاب والطالبات المستجيبين للاختبار . باسل التأكل من صدق الاختبار : - الت اعتمدثُ في التحقق من صدق الاختبار على تحكيم عدد من الخبراء والمتخصصين في تعليم اللغة العربية للناطقين بلغات أخرى" باعتبار هذه الأحكام طريقة من طرق التحقق من صدق أدوات القياس

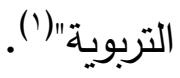

دار شعراوي، إحسان ويونس، فتحي، مقدمة في البحث التربوي، القاهرة:

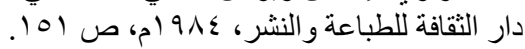


وهو المعنى نفسه في العربية، والمفخمة بالتركية تعني "قرد" فهي ليست نموذجا دقيقا، وكذلك استبدلت

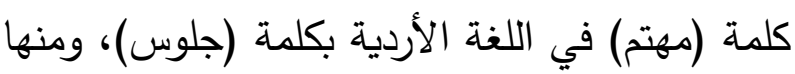

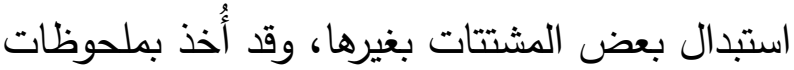

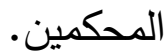

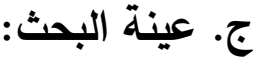

اللغات المختارة عينة للبحث، هي خمس لغات، تمثّل فصائل لغوية(') (عوائل) متتوعة، في مقابل اللغة فينة

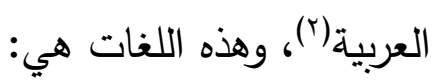

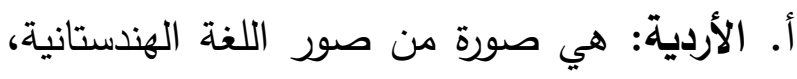

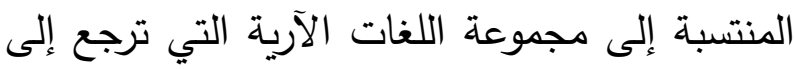

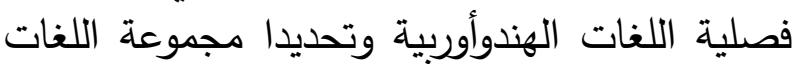

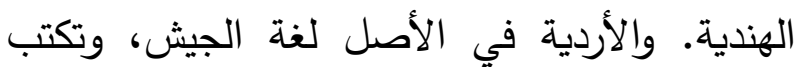

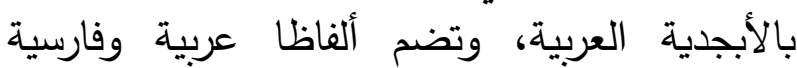
كثيرة، ولها صلة وثيقة باللغة العربية؛ إذ كانت العربية اللغة الرسمية في باكستان حقبة من الزمان إلى أن سيطر الإنجليز سيطرة كاملة على شبه القارة

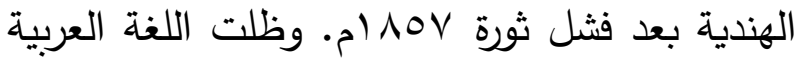
باقية معها في المحاكم الشرعية الرسمية ولغة التعليم

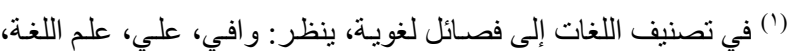

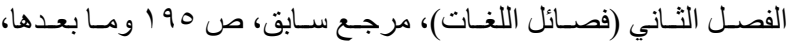

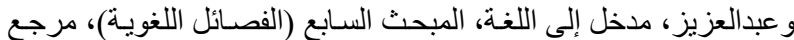

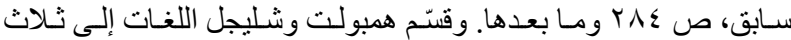

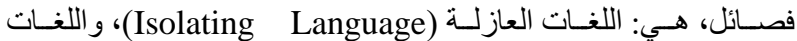

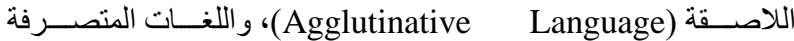
(Inflectional Language)

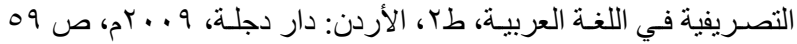
(r) اللغة العربيـة من فصيلة اللغات السـامية الأولى وتحديدا من السـامية

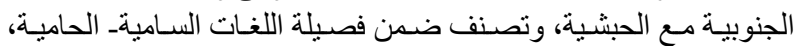

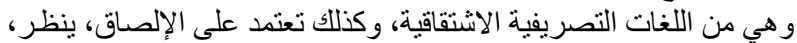

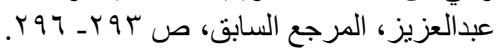

ووضع أمام كل بند من هذه البنود الأربعة خانة

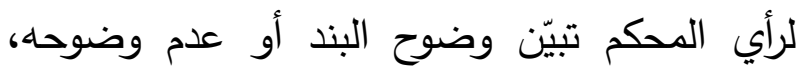
مناسبته أو عدم مناسبته، دقته أو عدم دقته. وللتأكد من صدق القائمة عرضت الاستمارة على مجموعة من الأساتذة المتخصصين في تعليم اللغة العربية للناطقين بلغات أخرى، وعلم الاستهاة اللغة التطبيقي، وفي المناهج وطرائق تدريس اللغة العربية، وعلم المصطلح وصناعة المعجمات، وعددهم (IV)

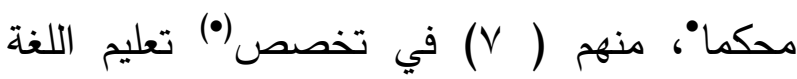
العربية للناطقين بلغات أخرى، و( r ب) في تخصص علم اللغة التطبيقي، و(Y) في تخصص اللسانيات التطبيقية، و(Y) في تخصص اللغويات، و(Y) في تخصص المناهج وطرق التدري، و(1) في القياس والتقويم في اللغة العربية للناطقين بغيرها والاختبارات اللغوية، واستهدف التحكيم أساتذة من المتخصصين في تعليم اللغة العربية الناطقين باللغات المستهدفة من الاختبار ، ولغاتهم الأم هي: الأردية، والإندونيسية، والتركية، والملايوية، والهوسا. وبعد التحكيم جمعت ملحوظات السادة الدحكين وتم ضبط صياغة الجمل والخيارات بناء عليها، ومن التعديلات المقترحة استبعاد بعض البنود واستبدالها بغيرها، مثل استبعاد كلمة "ميمون" في اللغة التركية واستبدالها بكلمة "عادي"؛ لأن كلمة "ميمون" في لئي التركية تنطق مرققة ومفخمة، فالمرققة تعني "مبارك"

• الملحق (؟) ويمكن الاطلاع على قائمة المحكمين من خلال التو اصل مع الباحث على البريد الإلكتروني: Kalhogory @ kau.edu.sa • ذكرت التخصصات العلمية للسادة المحكمين حسب ما ورد منهم عند

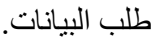




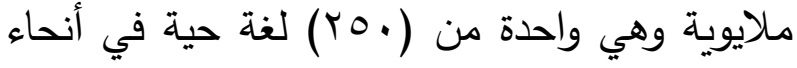

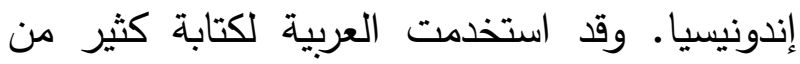
الآثار الأدبية الإندونيسية والآداب المحلية المكتوبة

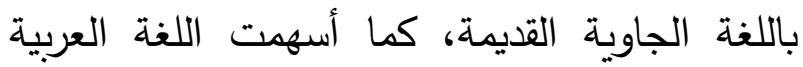
بعدد هائل من مفرداتها في سبيل إثراء اللغهاء التها الإندونيسية(ץ)، وقد ذكرت بعض مغ الدرداستات أن عدد

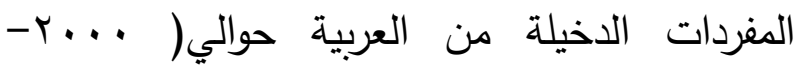

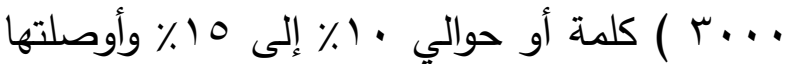

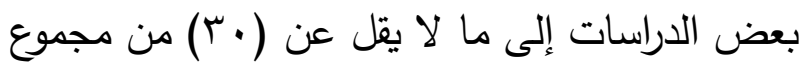
المفردات في المعجم (r). ج. التركية: وهي من فصيلة اللغات الأوراليةالألطائية التي تضم مجموعة كبيرة من اللغات، ويقسمها العلماء إلى مجموعتين، اللغات الأورالية

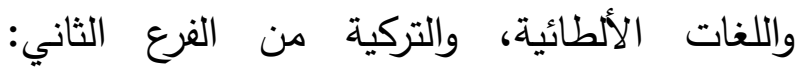
الألطائية ومعها المنشورية والمغولية. وتصنف هذه الفصيلة ضمن الفصائل اللغوية الأخرى، واللغة والفة ولهية

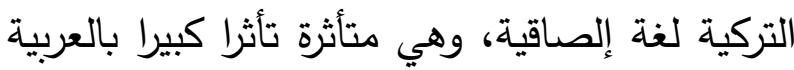
والفارسية، وكانت تكتب بالحروف العربية، ثم حلّت الحروف اللاتينية محلها في عهد مصطفى كمال

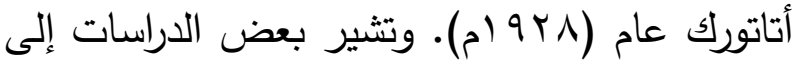

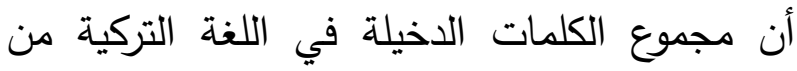
اللغة العربية (T7 آ7) كلمة، وهي أعلى نسبة مقارنة

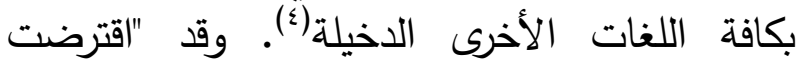

(r) مجموعة باحثين، اللغة العربية في إندونيسيا، طا، الرياض: مركز

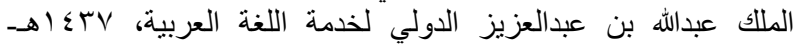
.

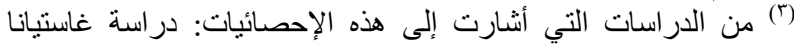

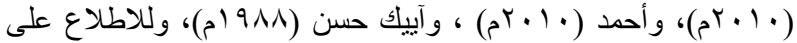

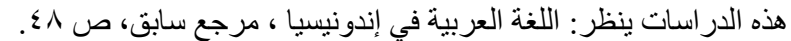

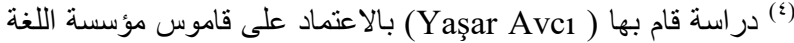

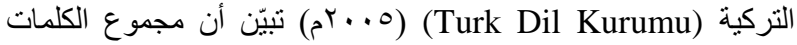

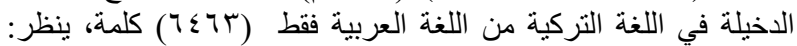
Yaşar Avcı, Arapça Kökenli Osmanlica Sözcükler, s. 7; bkz. Türk Dil Kurumu Türkçe Sözlük, Ankara,3448 s. 1-7 نقلا عن كتاب اللغة العربية في تركيا، لمجموعة باحثين، تحرير:

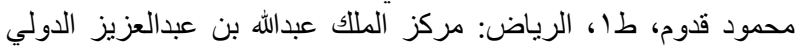

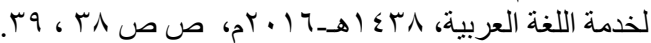

الإسلامي(r)، ثم استبدلت بها الفارسية. وبعد ذلك الإند

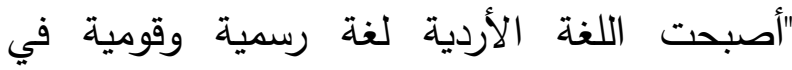

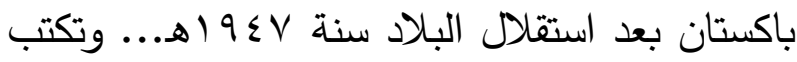
بالحروف العربية، وأكثر المفردات والكلمات فيها

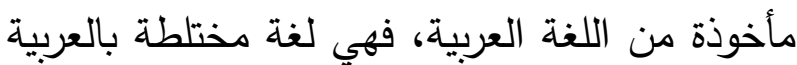
إلى حدّ كبير. كما لا تزال اللغة العربية باقية معها لإلها

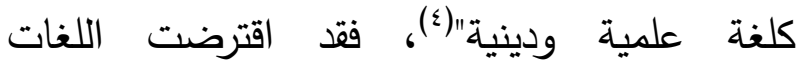
الباكستانية من اللغة العربية من المفردات أسماء

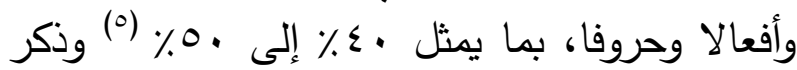
الباحث خالق ملك، ما نصده: "نجد تدخّل اللغة التة العربية في الأردية في حقل المفردات بنسبة مرنفة فئنة

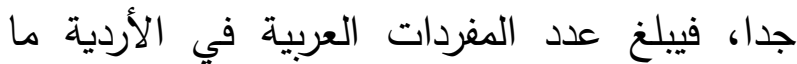

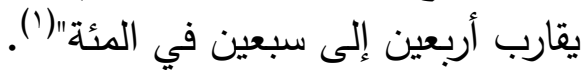

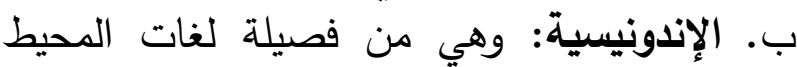
الهندي، وهي تتألف من فصائل لغوية لا يجمع بينها

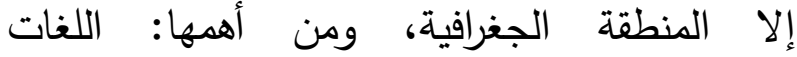

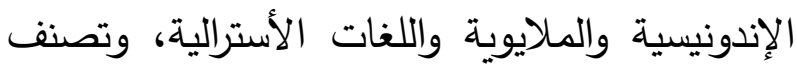

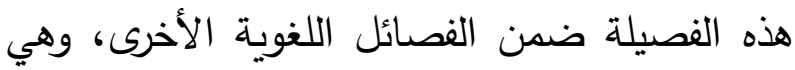
من اللغات الإلصاقية، واللغة الإندونيسية فرع من الفن الفية اللغة الملايوية أو لهجة قياسية للملايوية إلا أنها

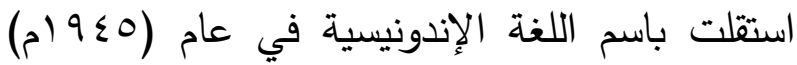

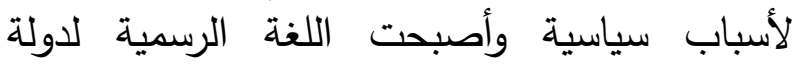

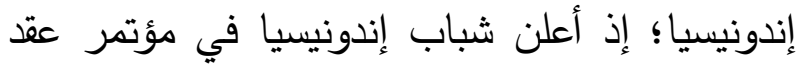

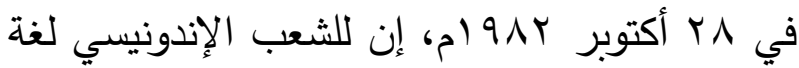

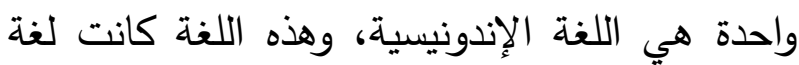

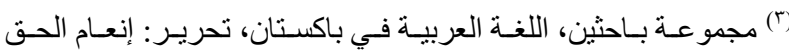

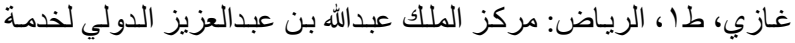

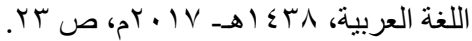

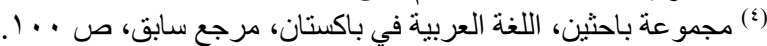

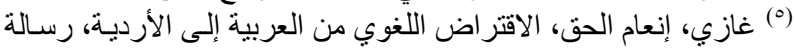

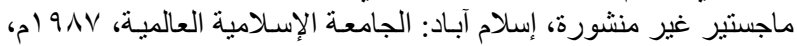

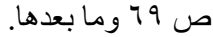

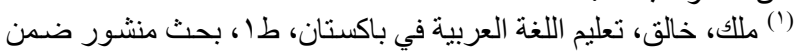

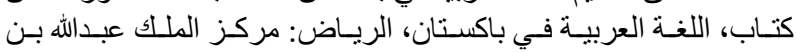

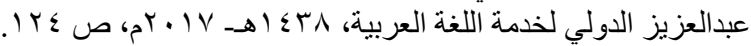


هـ. الهوسا: وهي من فصيلة اللغات السودانيةالغينية، وتصنف هذه الفصيلة ضمن الفصني ائل اللغوية الأخرى، وتنتشر الهوسا بين نهري النيجر والفولتا، ولها صلة وثيقة باللغة العربية، يقول تيجاني المسكين:" فقد انتشرت اللغة العربية و وثقافتها وازدهرت ازدهارا واسعا في بلاد نيجيريا، عبر

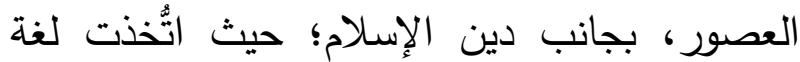

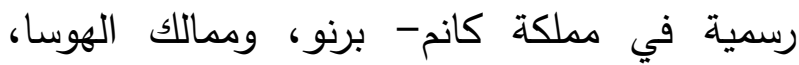
والخلافة العثمانية في سكوتو، وفيها كانت تصدر

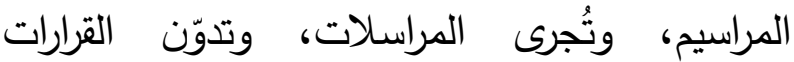

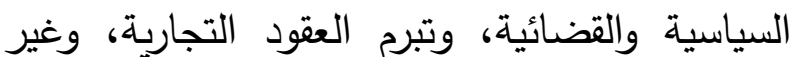
ذلك" (7)

وقد ذكر مصطفى حجازي، أن أهم الآثار الثقافية التي تركها العرب في أفريقيا هي كتابة لغة الهوسا

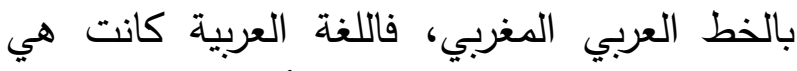
اللغة الرسمية السائدة في غرب أفريقيا حتى سيطرة

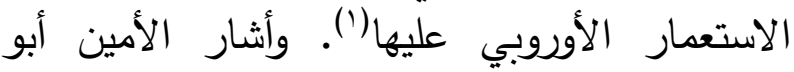
منقة، إلى أن لغة الهوسا من اللغات الهات القليلة ذات العلاقات مع اللغة العربية، وقد صنفت هذه العلاقات التهات

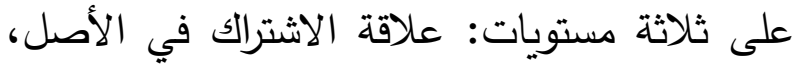

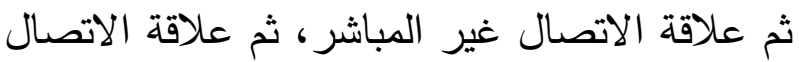

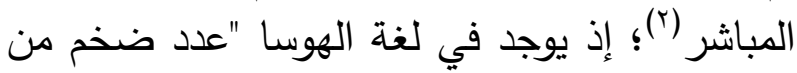

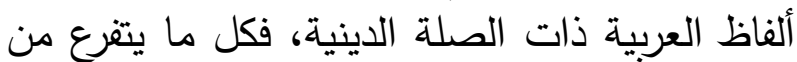

(آ) المسكين، تيجاني وآخرون، اللغة العربية في نيجيريا، طا، الرياض:

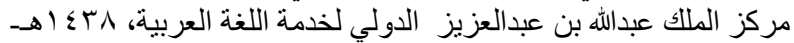
(V

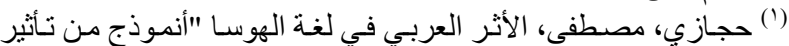

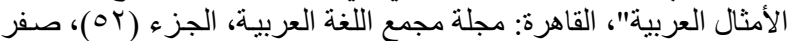

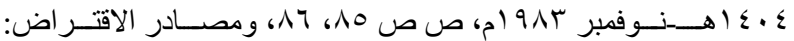

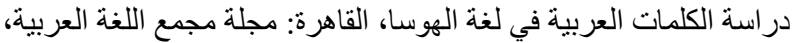

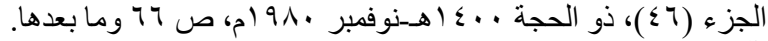

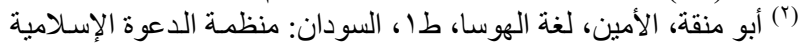

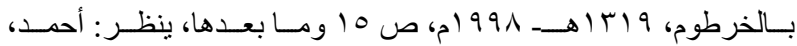

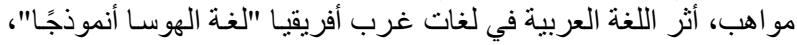

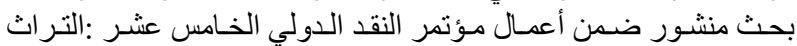

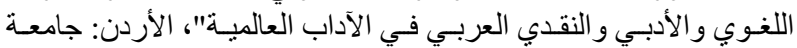

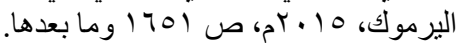

التركية كلمات عربية بعضها حافظ على دلالته

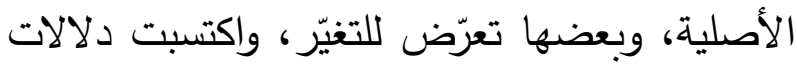

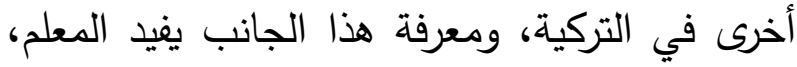
والمتعلم، ومصدمي المناهج الدراسية الموجهة لتعليم

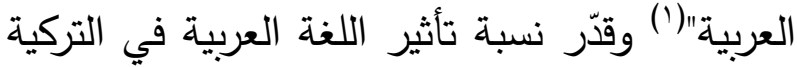

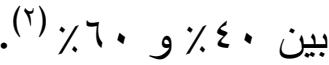
د. الملايوية: هي لغة ، لغ أوسترونيسية وهي من فصيلة لغات المحيط الهندي، وتصنف هذه الفصيلة ضين الفين الفصائل اللغوية الأخرى وتتنمي إلى فصيلة فيلة الملايو بولونيزية وتعرف في المجتمع الملايوي بـ "بهاسا ملايو"، وكانت العربية أداة وحيدة لكتابة اللغة لهائة

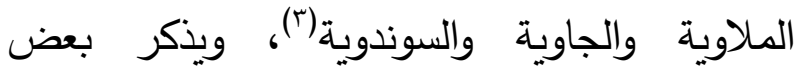

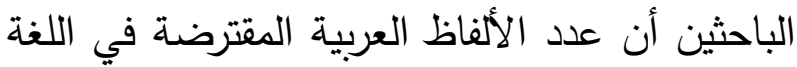

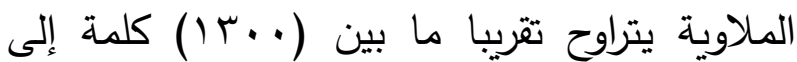

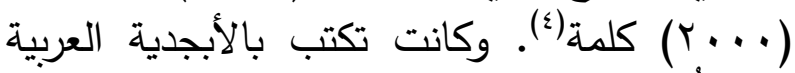

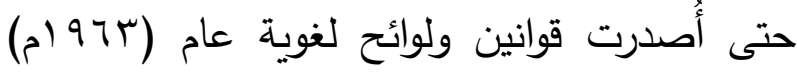
تتص على وجوب استخدام الحروف اللاتينية بديلا

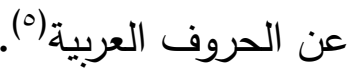

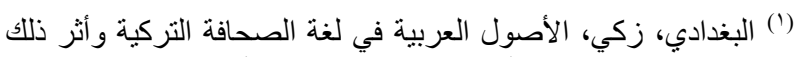

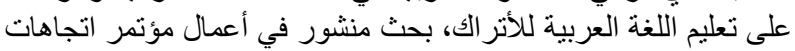

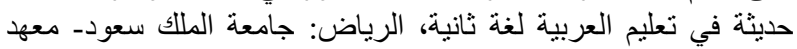

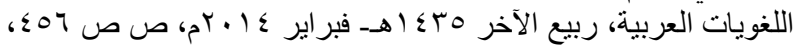
$\leqslant 90$

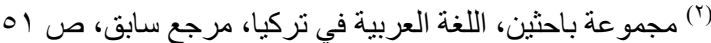

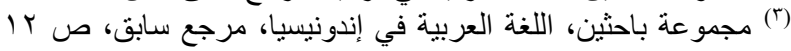

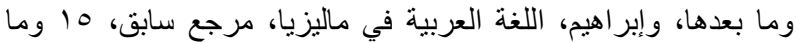

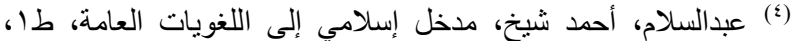

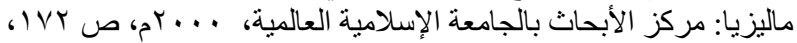
وينظر: ماليز

Beg, M. A. J., Arabic Loan- Word in Malay: A Comparative Study, Kuala Lumpur: The University of Malaya Press, 1979.

Hamdan, Abd Rahman , Tulisan Jawi Ke Arah ${ }^{\left({ }^{\circ}\right.}$ Penggunaan Dan Pengukuhan Yang Meluas. Seminar Bahasa Melayu dan Pembangunan Insan, 1998, p.11-13 
أما الكلمات المختارة عينة للبحث لإجراء الاختبار

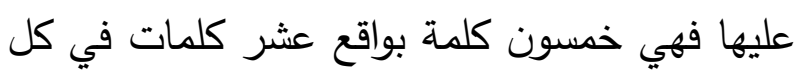

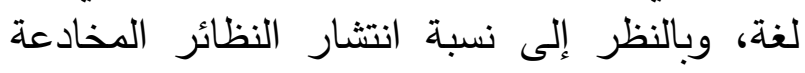

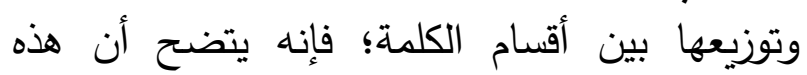
النظائر منتشرة في الأسماء بصورة أكثر وتوزيعها

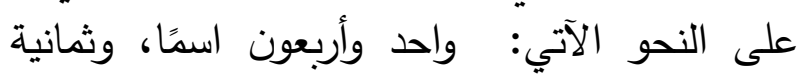
أفعال وحرف واحد، تكرر منها اسمان في اللغتين

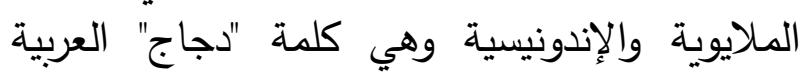

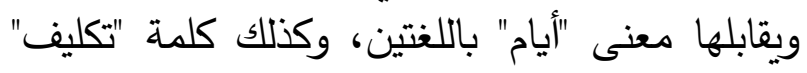

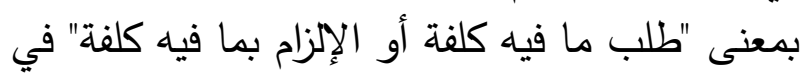
العربية ويقابلها معنيان مختلفان في الأردية والتركية؛ إذ تعني في الأردية "ألم ووجع" وفي التركية "|قتراح"، الأن التركية

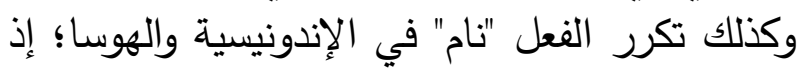

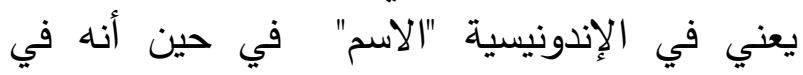

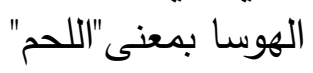

الصوم والصلاة والحج والزكاة والجهاد، يكاد يكون

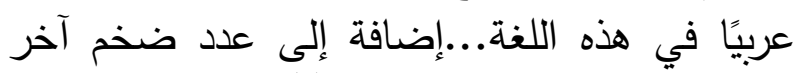

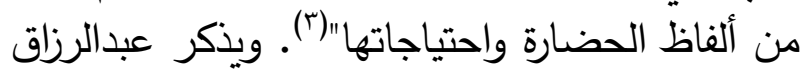

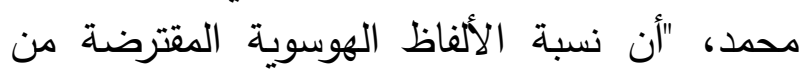

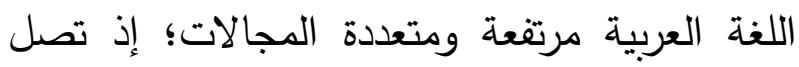

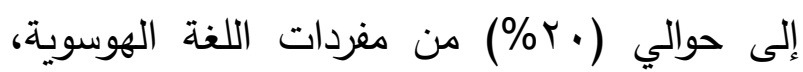
وهذا يشير إلى عمق الاتصال وقوته بين اللغتين

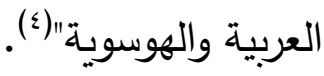
ويذكر نصر البغدادي، أن " مفردات كثيرة تسربت الإن الإني

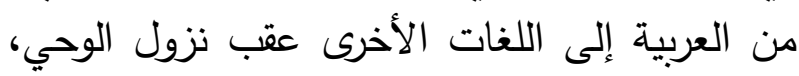

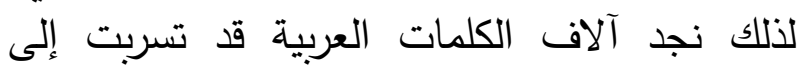

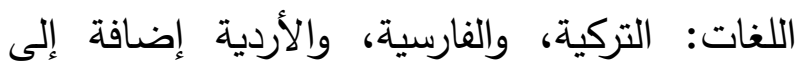
الإسبانية والبرتغالية والأفريقية والهندية والفية والمجرية

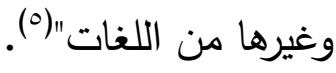

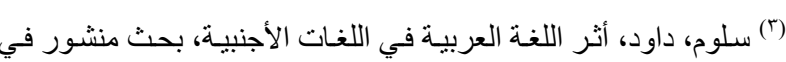

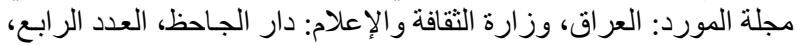

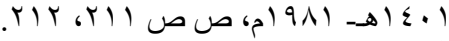

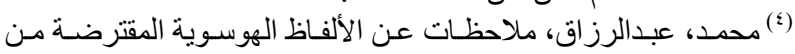

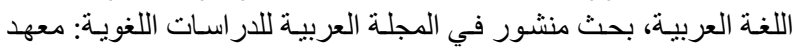

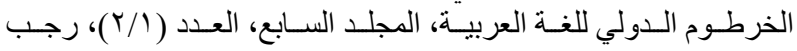

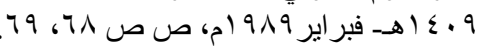

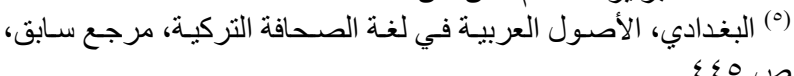


وتمثل الجداول الآتية النظائر المخادعة المختارة بين اللغة العربية واللغات الأخرى: أولا: النظائر المخادعة بين العربية والأردية

\begin{tabular}{|c|c|c|c|c|}
\hline \multicolumn{2}{|c|}{ الكلمة ومعناها باللغة الأردية(؟) } & \multicolumn{2}{|c|}{ الكلمة ومعناها باللغة العربية(') } & \\
\hline صحيفة أو جريدة & اخبار & جمع خبر، ما ينقل ويُحدّث به قولا أو & أخبار & 1 \\
\hline فجأة وصدفة & اتفاقي & 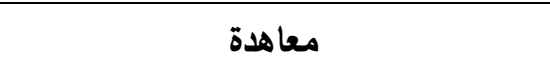 & اتفاقية & r \\
\hline ألم ووجع ألم & تكليف & طلب ما فيه كلفة أو الإلزام بما فيه كلفة & تكليف & $r$ \\
\hline وبمغنى مناسبة أيضًا & 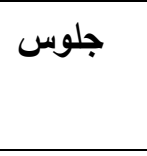 & قعود & 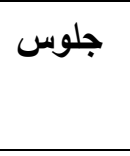 & $\varepsilon$ \\
\hline 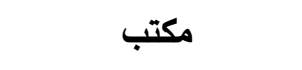 & 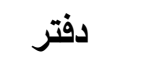 & 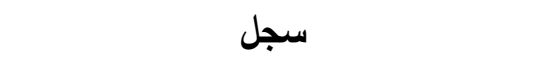 & 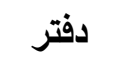 & $\bullet$ \\
\hline جيد ونفيس & 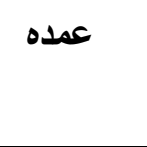 & السيد أو الذي يعتمد عليه قومه في أمر & 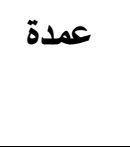 & 9 \\
\hline فقير & غريب & أجنبي & غريب & $v$ \\
\hline سرور ومتعة & 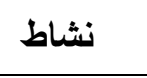 & ممارسة فعلية لعمل ما & 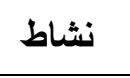 & $\wedge$ \\
\hline مشقة وجها & 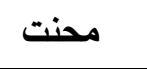 & مصيبة بلاء & 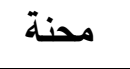 & 9 \\
\hline زحام وحشد & هجوم & ورود الثيء فجأة & 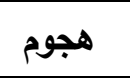 & 1. \\
\hline
\end{tabular}

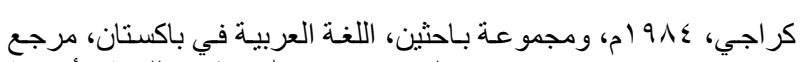

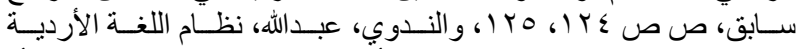

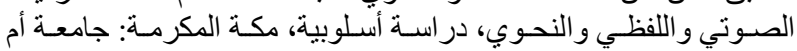

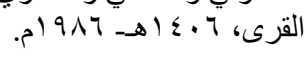

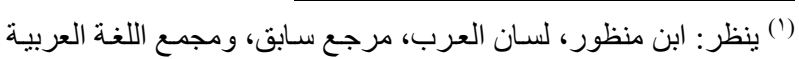

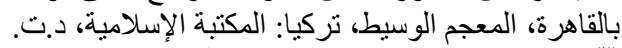

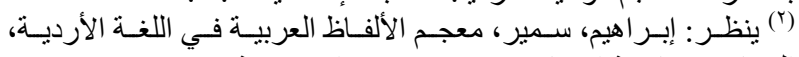

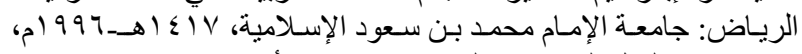

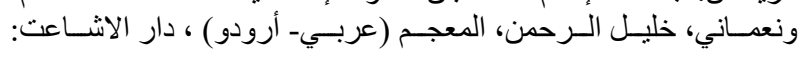


ثانيًا: النظائر المخادعة بين العربية الإندونيسية

\begin{tabular}{|c|c|c|c|c|}
\hline \multicolumn{2}{|c|}{$\begin{array}{l}\text { الكلمة ومعناها باللغفة } \\
\text { الإندونيسية(r) }\end{array}$} & \multicolumn{2}{|c|}{ الكلمة ومعناها باللغة العربية(') } & s \\
\hline غضب & Amarah & علامة & أمارة & 1 \\
\hline 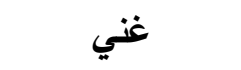 & Tajir & الذي يبيع ويشتري & 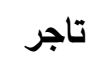 & r \\
\hline مقبرة & Turbah & أرض أرض & تربة & $r$ \\
\hline أيام & Ayam & طائر من الدواجن & 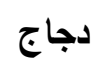 & $\varepsilon$ \\
\hline زيارة القبور فقط & Ziyarah & الإتيان بقصد رؤية الثخص أو & 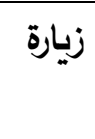 & 0 \\
\hline 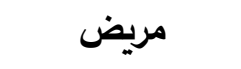 & Sakit & صامت & 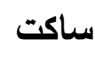 & 7 \\
\hline 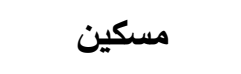 & Fallah & الذي يعمل في الزراعة & فلاّح & V \\
\hline غليظ & Kasar & هشم الثيء وحوّله إلى قطع صغيرة & كسر & $\wedge$ \\
\hline 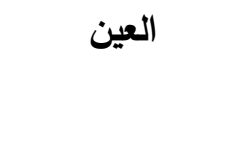 & Mati & الموت ضد الحياة ويغني خروج الروح & مات & 9 \\
\hline 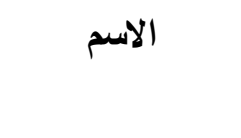 & Nama & الدلالة على الجمود وسكون الحركة & 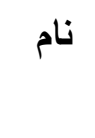 & 1. \\
\hline
\end{tabular}

(1) ينظر : الفيروزابادي، مجد الدين أبو طـاهر، القاموس المحبط، تحقيق:

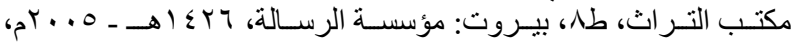

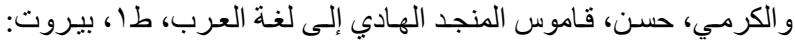

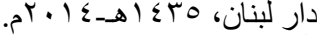

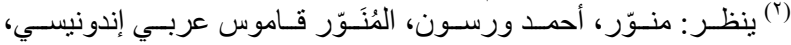

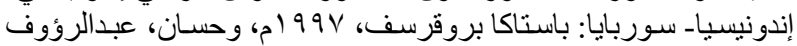

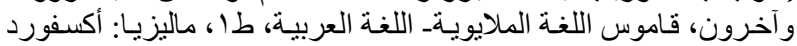

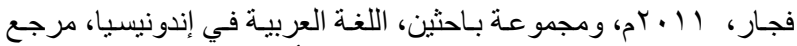

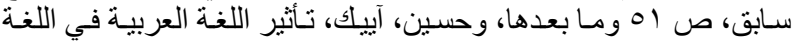

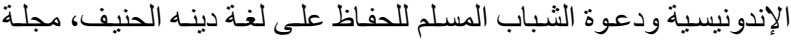

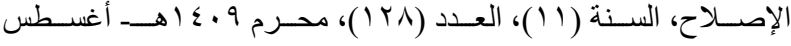


ثالثًا: النظائر المخادعة بين العربية وإلتركية

\begin{tabular}{|c|c|c|c|c|}
\hline \multicolumn{2}{|c|}{ الكلمة ومعناها باللغة التركية (†) } & \multicolumn{2}{|c|}{ الكلمة ومعناها باللغة العزبية(') } & 5 \\
\hline الحشيش & Esrar & الشيء المخفي & أسرار & 1 \\
\hline اقتراح & Teklif & طلب ما فيه كلفة أو الإلزام بما فيه & تكليف & r \\
\hline الطبيب أو المداوي & Hekim & العالم وصاحب الحكمة & 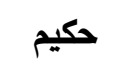 & r \\
\hline وجه & Surat & الثكل والهيئة & صورة & $\varepsilon$ \\
\hline حقير - ذليل & Adi & شيء مألوف أو معهود & عادي & 0 \\
\hline بمعنى الكفاح والنضال أو & Mucadele & المحاورة والمناظرة والمخاصمة & 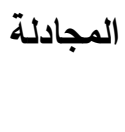 & 7 \\
\hline الأمر العظيم والمهيب & Muhtesem & الخجل والحياء والوقار & محتشم & V \\
\hline متاح ومتفرّغ & Musait & 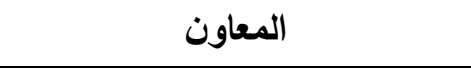 & المساعد & $\wedge$ \\
\hline ضيف- سائح & Misafer & المرتحل وعكسه المقيم & مسافز & 9 \\
\hline المدرسة & Mektep & طاولة يكتب عليها/ مكان عمل & مكتب & 1 . \\
\hline
\end{tabular}

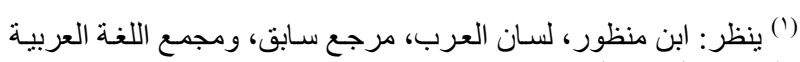

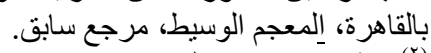

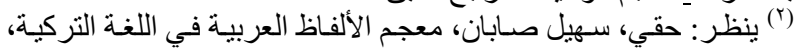

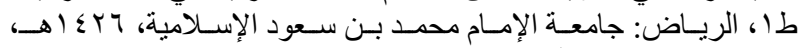

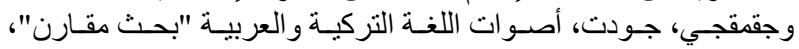

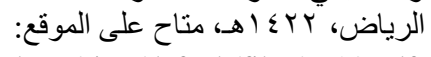
fac.ksu.edu.sa/sites/default/files/6_28.pdf

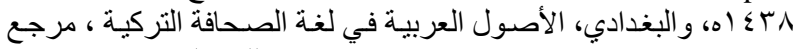

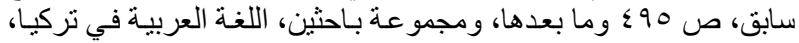

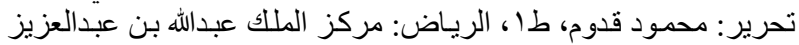

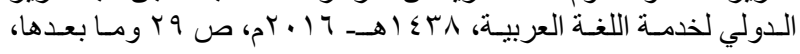

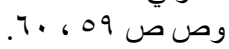


رابعًا: النظائر المخادعة بين العربية وإلملايوية

\begin{tabular}{|c|c|c|c|c|}
\hline \multicolumn{2}{|c|}{ الكلمة ومعناها باللغة الملايوية_(؟) } & \multicolumn{2}{|l|}{ الكلمة ومعناها باللغة العزبية(1) } & p \\
\hline جيد، طيب، صادق & Betul & البتول من النساء العذراء المنقطعة من الأزواج & بتول - & 1 \\
\hline 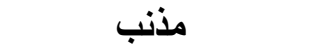 & Bersalah & مكتوب يرسل إلى شخص لإعلامه بشيء ما & 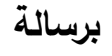 & r \\
\hline المدرسة الاينية أو & Pondok & شجر له ثمر صغير، عبارة عن كرة في حجم & 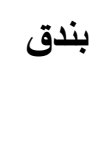 & $r$ \\
\hline 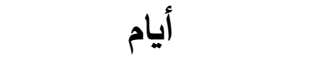 & Ayam & طائر من الاواجن & 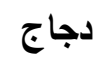 & $\varepsilon$ \\
\hline العيد أو الشيء الكبير & Raya & 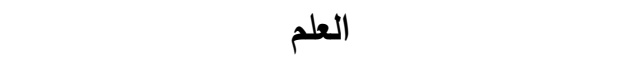 & راية & $\bullet$ \\
\hline مزهرية أو الجرة & Pasu & آلة يحفر بها ويقطع & فأس & 7 \\
\hline صحن أو طبق & Pinggan & فنجان القهوة & فنجان & V \\
\hline معقول أو مقبول & Munasabah & 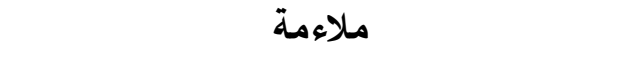 & 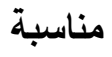 & $\wedge$ \\
\hline أرز مطبوخ & Nasi & إغفال الثيء وتركه & 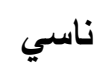 & 9 \\
\hline 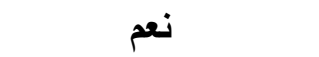 & Ya & حرف نداء للقريب أو البعيد & يا & 1 . \\
\hline
\end{tabular}

اللغة الملايويةـ اللغة العربية، مرجع سابق، وإبراهيم وآخرون، اللغة العربية في ماليزيا، مرجع سابث. للفة العربية

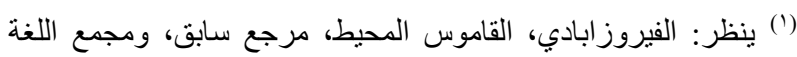

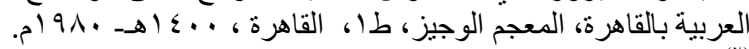

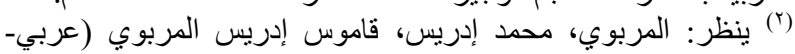

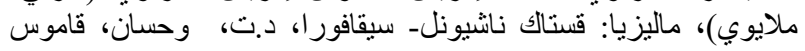


خامسًا: النظائر المخادعة بين العربية والهوسا

\begin{tabular}{|c|c|c|c|c|}
\hline \multicolumn{2}{|c|}{ الكلمة ومعناها بلغة الهوسا(ץ) } & \multicolumn{2}{|c|}{ الكلمة ومعناها باللغة العربية(1) } & r \\
\hline فارغ & BABU & فتحة للاخول أو الخروج من المكان & باب & 1 \\
\hline ضيوف & BAQIY & الذي لا ينتهي تقدير وجوده (أبدي الوجود - & بقي & r \\
\hline 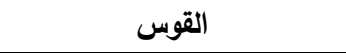 & BAKA & 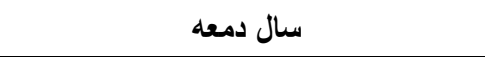 & 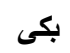 & $r$ \\
\hline بليد & DAQIQI & الطحين، وقليل الخير، والأمر الغامض، & دقيق & $\varepsilon$ \\
\hline رقص - ت إ & RAWA & نقل حدثًا ووصفه، ومنه سرد الرواية & 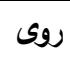 & ○ \\
\hline الآلة التي تستعمل لقفل الباب & SAKATA & ص صت & 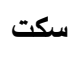 & 7 \\
\hline 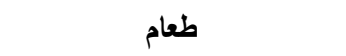 & GAYA & نهاية & 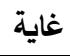 & $v$ \\
\hline راحة & HUTU & سمك & 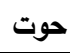 & $\wedge$ \\
\hline 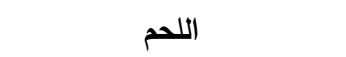 & NAMA & رقد & 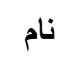 & 9 \\
\hline التثاؤب & HAMMA & عزم على فعل شيء & همَ & $1 \cdot$ \\
\hline
\end{tabular}

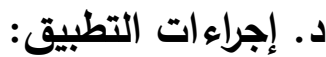

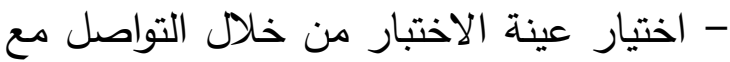
الجهات التعليمية التي تُعنى بتعليم اللغنة العربية التعارية للناطقين بإحدى اللغات المحددة.

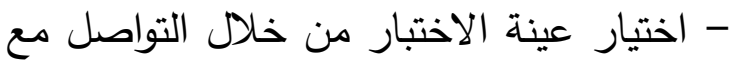
الجهات التعليمية التي تُعنى بتعليم اللغة العربية التعارية للناطقين بإحدى اللغات المحددة. - التعاون مع الزملاء في الجهات التعليمية

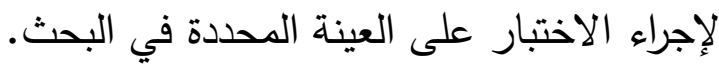

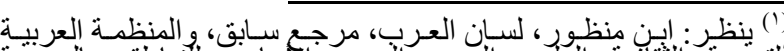

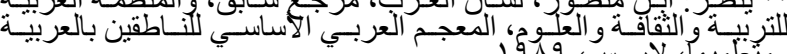

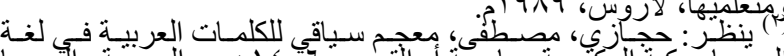

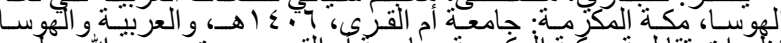

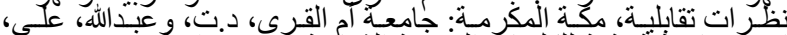

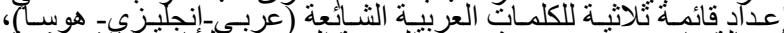

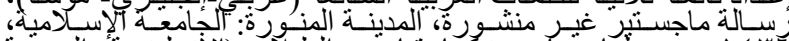

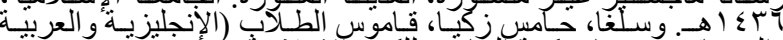




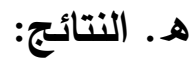

توضّح الجداول الآتية استجابة عينة البحث من الطلاب والطالبات الناطقين باللغات الخمسة المحددة في البحث.

جدول (1)

استجابة عينة البحث من الطلاب والطالبات الناطقين باللغة الأردية

\begin{tabular}{|c|c|c|c|c|c|c|}
\hline \multicolumn{6}{|c|}{ استجابة الطلبة } & \multirow[t]{3}{*}{ الفقرة• } \\
\hline \multicolumn{2}{|c|}{ المشتتان الآخران } & \multicolumn{2}{|c|}{ النظير المخادع } & \multicolumn{2}{|c|}{ الإجابة الصحيحة } & \\
\hline النسبة & ت & النسبة & ت & النسبة & • & \\
\hline$r, r r$ & 1 & - & - & $97,7 \vee$ & rq & 1 \\
\hline $17,7 V$ & $\bullet$ & $r$. & 9 & or,r & 17 & r \\
\hline Ir,rr & $\varepsilon$ & $\Lambda r, r r$ & ro & r & 1 & $r$ \\
\hline$r, r r$ & 1 & Or,rr & 17 & $\varepsilon r, r r$ & ir & $\varepsilon$ \\
\hline $17,7 V$ & 0 & $r q, 7 v$ & $\wedge$ & $07,7 \vee$ & IV & $\bullet$ \\
\hline$\varepsilon$. & ir & $07,7 \vee$ & iv & $r, r r$ & 1 & 7 \\
\hline Y ४, ४ & $\wedge$ & L & ir & $r$. & 9 & $v$ \\
\hline$\varepsilon 7,7 \vee$ & $1 \varepsilon$ & $r$. & 9 & rr,rr & v & $\wedge$ \\
\hline$\varepsilon$ & ir & $7,7 V$ & r & rr,rr & 17 & 9 \\
\hline$\varepsilon r, r r$ & ir & $17,7 \vee$ & $\bullet$ & $\varepsilon$ & ir & 1. \\
\hline ro & vo & $r \varepsilon, 7 v$ & $1 \cdot \varepsilon$ & $\varepsilon, r r$ & $|r|$ & المجموع \\
\hline
\end{tabular}

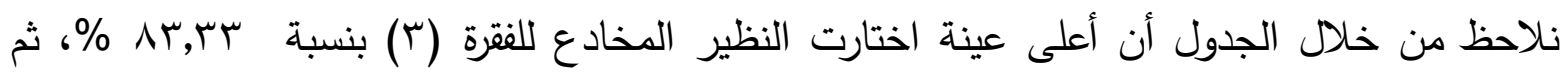

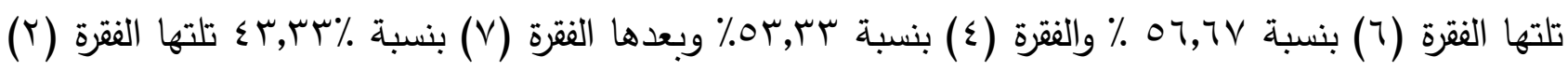

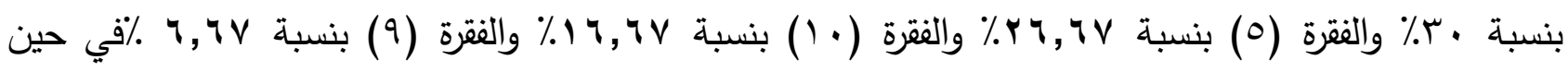

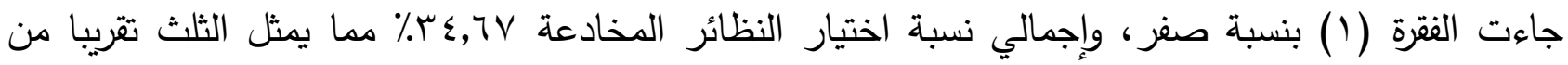
عينة الدراسة، وبهذا يظهر أثر النظائر المخادعة على متعلمي اللغة العربية الناطقين باللغة الأردية. 


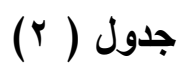

استجابة عينة البحث من الطلاب• الناطقين باللغة الإندونيسية

\begin{tabular}{|c|c|c|c|c|c|c|}
\hline \multicolumn{6}{|c|}{ استجابة الطلبة } & \multirow[t]{3}{*}{ الفقرة } \\
\hline \multicolumn{2}{|c|}{ المشتتان الآخران } & \multicolumn{2}{|c|}{ النظير المخادع } & \multicolumn{2}{|c|}{ الإجابة الصحيحة } & \\
\hline النسبة & $ت$ & النسبة & $ت$ & النسبة & $ت$ & \\
\hline 1. & $r$ & r,rr & 1 & 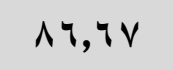 & ז & 1 \\
\hline 1. & $r$ & . & . & $\Lambda \leqslant, r \vee v$ & $r v$ & r \\
\hline IT,rr & $\varepsilon$ & . & . & 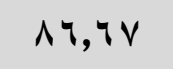 & rq & $r$ \\
\hline $7,7 V$ & r & . & - & qr,rr & rی & $\varepsilon$ \\
\hline rr,rr & 19 & . & . & rq, TV & 11 & 0 \\
\hline . & - & $r, r r$ & 1 & $97,7 \vee$ & rq & 7 \\
\hline Ir,rr & $\varepsilon$ & $7,7 \mathrm{~V}$ & r & $\wedge$. & $r \varepsilon$ & $v$ \\
\hline 1. & $r$ & 1. & $r$ & $\wedge$. & $r \varepsilon$ & $\wedge$ \\
\hline 1. & $r$ & . & . & $\Lambda \varepsilon, r \vee v$ & $r V$ & 9 \\
\hline r $7,7 V$ & $\wedge$ & r,rr & 1 & $v$. & $M_{1}$ & 1. \\
\hline Tr, & $\leqslant 9$ & r,TV & $\wedge$ & 11 & $r \leqslant r$ & المجموع \\
\hline
\end{tabular}

نلاحظ من خلال الجدول أن العينة التي اختارت النظير المخادع حصلت على أقل نسبة؛ إذ إنها لم

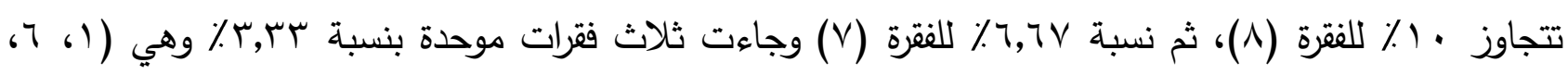

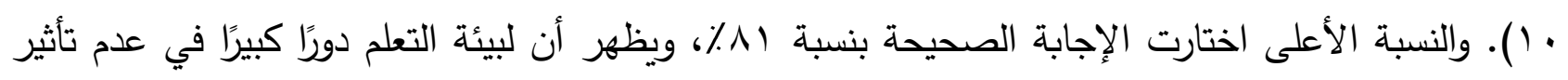

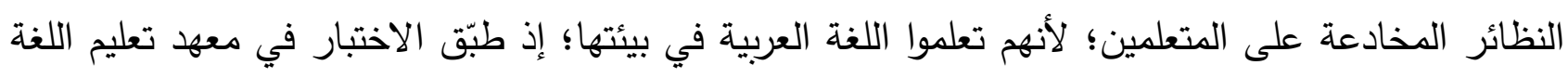
العربية لغير الناطقين بها في الجامعة الإسلامية في المدينة المنورة. 


\section{جدول (r)}

استجابة عينة البحث من الطلاب والطالبات الناطقين باللغة التركية

\begin{tabular}{|c|c|c|c|c|c|c|}
\hline \multicolumn{6}{|c|}{ استجابة الطلبة } & \multirow[t]{3}{*}{ الفقرة } \\
\hline \multicolumn{2}{|c|}{ المشتتان الآخران } & \multicolumn{2}{|c|}{ النظير المخادع } & \multicolumn{2}{|c|}{ الإجابة الصحيحة } & \\
\hline النسبة & $ت$ & النسبة & $ت$ & النسبة & $ت$ & \\
\hline 7. & 11 & $\varepsilon$. & ir & . & . & 1 \\
\hline rr,rr & $v$ & $\varepsilon r, v_{0}$ & $1 \varepsilon$ & $r$. & 9 & r \\
\hline ro & $\wedge$ & 1. & $r$ & זr, & 19 & $r$ \\
\hline r. & 9 & rr,rr & v & צ & $1 \varepsilon$ & $\varepsilon$ \\
\hline$\leq \neg, \wedge \vee$ & 10 & 17,79 & 0 & & 1. & 0 \\
\hline 7,77 & $r$ & - & . & $q r, r r$ & rی & 7 \\
\hline 1. & $r$ & $r, r r$ & 1 & $\wedge \neg, \uparrow \vee$ & $r q$ & v \\
\hline 1. & $r$ & Ач, ฯ & r & $r, r r$ & 1 & $\wedge$ \\
\hline$\cdot$ & · & Ir,rr & $\varepsilon$ & $\Lambda ч, 7 \vee$ & rq & 9 \\
\hline $1 \wedge, \vee \bullet$ & 9 & Tr,rr & $\varepsilon$ & צ & $r$. & 1. \\
\hline Tr,t & vi & $r \otimes, r r$ & VI & 01 & lor & المجموع \\
\hline
\end{tabular}

نلاحظ من خلال الجدول أن أعلى عينة اختارت النظير المخادع للفقرة (^) بنسبة ؟7,، ٪ ٪، ثم تلتها

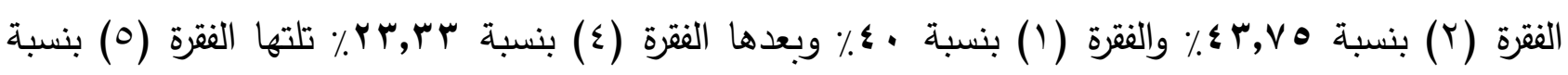

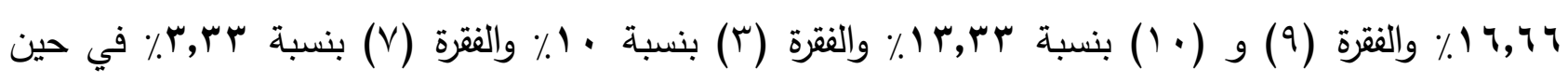

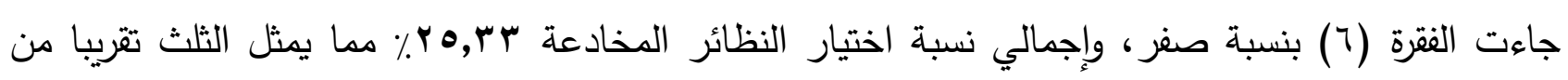
عينة الدراسة، ويتبيّن أن للنظائر المخادعة أثرًا على متعلمي العربية الناطقين باللغة التركية النئة 


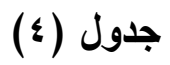

استجابة عينة البحث من الطلاب والطالبات الناطقين باللغة الملايوية

\begin{tabular}{|c|c|c|c|c|c|c|}
\hline \multicolumn{6}{|c|}{ استجابة الطلبة } & \multirow[t]{3}{*}{ الفقرة } \\
\hline \multicolumn{2}{|c|}{ المشتتان الآخران } & \multicolumn{2}{|c|}{ النظير المخادع } & \multicolumn{2}{|c|}{ الإجابة الصحيحة } & \\
\hline النسبة & $ت$ & النسبة & $ت$ & النسبة & $ت$ & \\
\hline v. & ri & $17,7 V$ & 0 & rr, & $\varepsilon$ & 1 \\
\hline Or, rr & 17 & rr,rr & 1. & rr, & $\varepsilon$ & r \\
\hline rq, TV & $\wedge$ & $r, r r$ & 1 & v. & ri & $r$ \\
\hline $7,7 V$ & $r$ & rr,rr & $v$ & v. & r & $\varepsilon$ \\
\hline Y , TV & $\wedge$ & rr, & 17 & r. & 7 & 0 \\
\hline · & • & $r, r r$ & 1 & $97,7 \vee$ & rq & 7 \\
\hline r. & 7 & $07, T \vee$ & IV & & $v$ & $v$ \\
\hline . & - & $\cdot$ & - & $1 \ldots$ & $r$. & $\wedge$ \\
\hline r. & 9 & Or,rr & 17 & $17,7 V$ & 0 & 9 \\
\hline Ir,rr & $\varepsilon$ & $r$. & 9 & $04,7 V$ & iv & 1. \\
\hline \% & $V \varepsilon$ & $\% r V, r r$ & Ar & $\% \leqslant \wedge$ & $1 \leqslant \varepsilon$ & المجموع \\
\hline
\end{tabular}

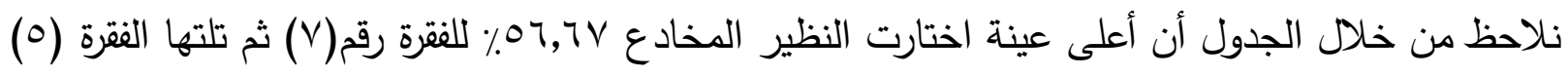

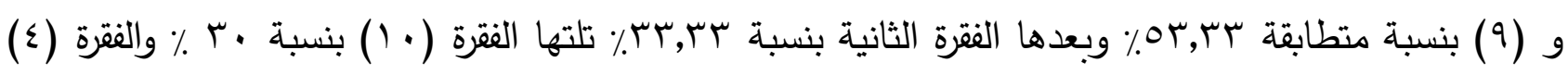

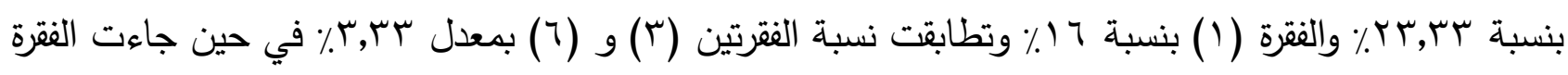

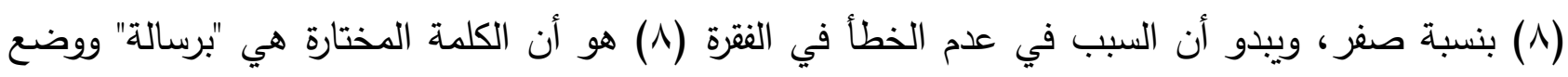

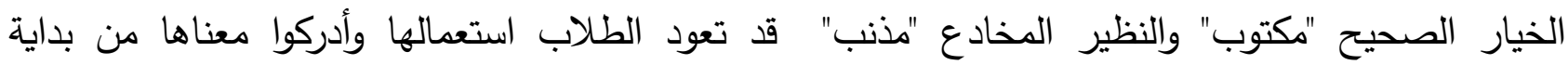
تعليمهم؛ إذ إنها شائعة الاستعمال والسياق أظهر معناها مما جعل الطلاب والطالبات جميعًا لم يخطئوا فيها. سواء باختيار النظير المخادع أم المشتين الآخرين.

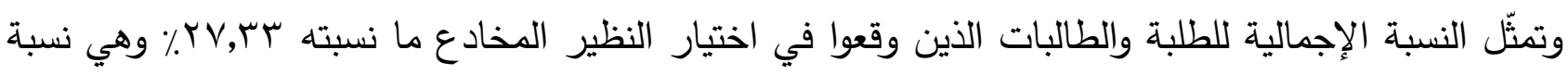
مرتفعة إذ تمثل أعلى من ربع العينة بقليل، ولهذا يتضح أثر النظائر المخادعة على متعلمي العربية الناطقين

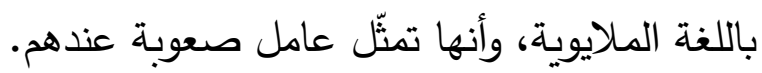


جدول (0)

استجابة عينة البحث من الطلاب• الناطقين باللغة الهوساوية (0)

\begin{tabular}{|c|c|c|c|c|c|c|}
\hline \multicolumn{6}{|c|}{ استجابة الطلبة } & \multirow[t]{3}{*}{ الفقرة } \\
\hline \multicolumn{2}{|c|}{ المشتتان الآخران } & \multicolumn{2}{|c|}{ النظير المخادع } & \multicolumn{2}{|c|}{ الإجابة الصحيحة } & \\
\hline النسبة & $ت$ & النسبة & $ت$ & النسبة & ت & \\
\hline$\varepsilon$. & Ir & $r, r r$ & 1 & Vד, צד & IV & 1 \\
\hline$r$. & 9 & r, & 1 & V $4, T V$ & rr & $r$ \\
\hline$\varepsilon$ & ir & • & • & $07, Y 0$ & 11 & $r$ \\
\hline rr,rr & v & . & . & $\vee \neg, 7 \vee$ & rr & $\varepsilon$ \\
\hline $17,7 \mathrm{~V}$ & 0 & 每 & 1 & $\wedge$. & $r \varepsilon$ & 0 \\
\hline 17,78 & 0 & $r, r \mu$ & 1 & $\wedge$. & $r \varepsilon$ & 1 \\
\hline 17,4 & 0 & . & . & AT,rr & ro & v \\
\hline Y, Yo & r & r,r & 1 & $\Lambda \varepsilon, r \vee \Delta$ & $r V$ & $\wedge$ \\
\hline . & . & $r, r r$ & 1 & $94,7 \vee$ & rq & 9 \\
\hline$r$. & 9 & . & . & v. & r & 1. \\
\hline YI & Tr & $r$ & 1 & VV & YTI & المجموع \\
\hline
\end{tabular}

نلاحظ من خلال الجدول أن العينة التي اختارت النظير المخادع حصلت على أقلّ نسبة؛ إذ جاءت

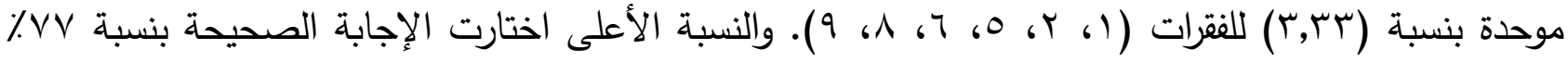
ويظهر أن لبيئة التعلم دورًا كبيرًا في عدم تأثير النظائر المخادعة على المتعلمين؛ لأنهم تعلموا اللغة العربية في بيئتها؛ إذ طبّق الاختبار في معهد تعليم اللغة العربية لغير الناطقين بها في الجامعة الإسلامية في المدينة المنورة. 
(7) الجدول

تكرارات أخطاء المستجيبين للاختبار باختيار النظير المخادع، والنسب المئوية مرتبة تنازليًا

\begin{tabular}{|c|c|c|}
\hline النسبة & التكرار & اللغات المستهدفة \\
\hline VT, & $1 . \varepsilon$ & الأردية \\
\hline$r V, r r$ & Ar & الملايوية \\
\hline ro,rr & IV & التركية \\
\hline$r, \vee \uparrow$ & $\wedge$ & الإندونيسية \\
\hline r & 7 & الهوسا \\
\hline$i v, \Lambda$ & YTV & المجموع \\
\hline
\end{tabular}

نلاحظ من تكرار أخطاء المستجيبين للاختبار أن تأثير النظائر المخادعة يظهر بنسبة أعلى عند الناطقين باللغة الأردية ثم الملايوية وبعدها التركية ويظهر أقل نسبة عند الهوسا وأكثر منها بقليل عند الناطقين باللغة الإندونيسية. ويبدو أن السبب في عدم تأثير النظائر المخادعة على الناطقين بلغة الهوسا والإندونيسية يعود إلى نى

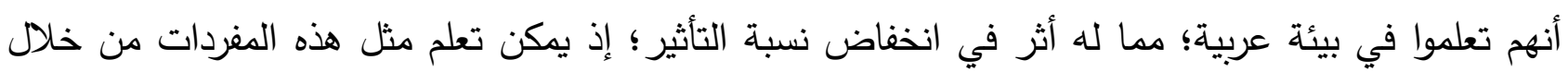
المجتمع الذين يعيشون فيه والبيئة التعليمية التي يتعلمون فيها. 
مراعاة تقديم النظائر المخادعة؛ إذ يتم الربط بين المعلومات الجديدة التي يتلقاها المتعلم بالمعلومات القديمة والهفاهيم التي يعرفها من قبل، وسبق له أن اكتسبها، وهذا ما يعرف بالتعلّم المعرفي. • يمكن توظيف النظائر المخادعة بطرائق مختلفة

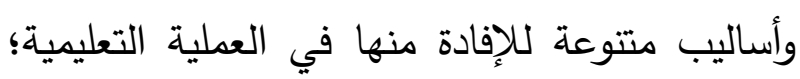

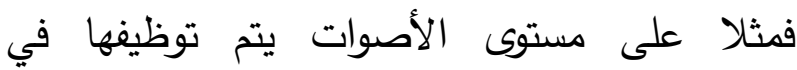
المستوى المبتدئ للإفادة من تعلُّم نطق الأصوات

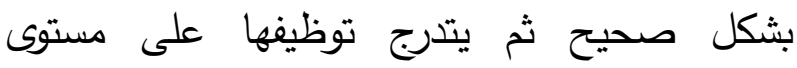
المفردات والتراكيب تدريجيا حسب احتياجات المتعلمين ومستوياتهم اللغوية كلما تقدّم المستوى لـاني التعليمي حتى يصل إلى المستويات المتقدمة لتظهر الإفادة منها في الترجمة بين اللغات وتوظيفها في التعبيرات الاصطلاحية والمجازية ...إلخ. وأقترح دراسات مستقبلية تعنى بـ: • رصد الألفاظ المشتركة بين اللغة العربية واللغات الأخرى، والإفادة منها في تعليم العربية وتأليف المناهج وتصميم البرامج التعليمية.

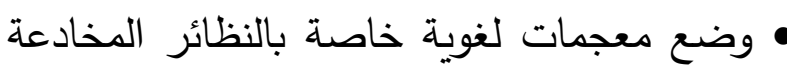
بين اللغة العربية واللغات الأخرى على غرار المعجمات الموجودة في اللغات الغربية.
ونصل إلى النتائج النهائية؛ إذ تبيّن من خلال التطبيق والتحليل ما يأتي: • تظهر النظائر المخادعة بشكل جليّ في اللغات

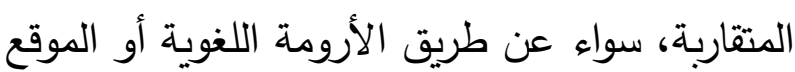
الجغرافي أو الاتصال الثقافي أو التجاري أو غيرها. توجد النظائر المخادعة في كل اللغات ولا تتحصر في اللغات المتقاربة، ونشأت هذه الألفاظ عن طريق الاقتراض والتأثير المتبادل بين اللغات. • تؤثر النظائر المخادعة على المتعلمين في تعلّم اللغة العربية، ويتفاوت التأثير حسب المستوى العلمي للمتعلمين؛ إذ ظهر تأثيرها على طلاب المستوى

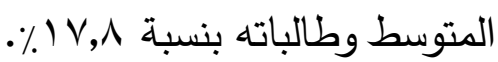
•تكثف استجابات الطلاب انخفاض تأثير النظائر المخادعة على متعلمي العربية الناطقين بلغات أخرى في بيئة عربية.

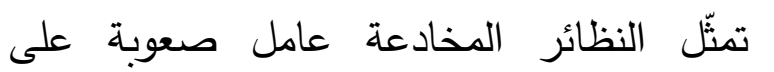
مستوى المفردات عند متعلمي اللغة العربية الناطقين

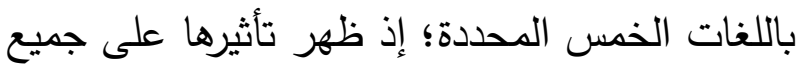
المتعلمين من خلال اختيارها بديلا عن الإجابة الصحيحة، وتتفاوت نسبة الصعوبة عند المتعلمين. وأخيرا فإنني أوصي بما يأتي:

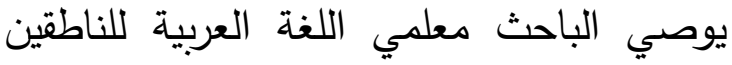
بلغات أخرى ومصمي البرامج ومؤلفي المناهج 
البغدادي، زكي، الأصول العربية في لغة

الصحافة التركية وأثر ذلك على تعليم اللغة العربية للأتراك، بحث منشور في أعمال مؤتمر اتجاهات حديثة في تعليم العربية لغة ثانية، الرياض: جامعال الملك سعود-معهد اللغويات العربية، ربيع الآخر

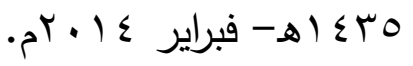

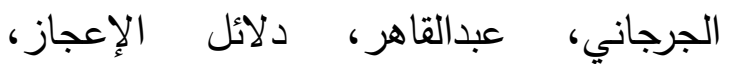
صححه: محمد عبده ومحمد رضا، بيروت: دار

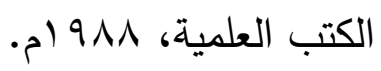

جقدقي، جودت، أصوات اللغة التركية والعربية

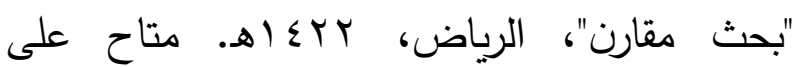
fac.ksu.edu.sa/sites/default/files/6_28.pdf الموقع

جيولك، يعقوب وقدوم، محود، الحصيلة اللغوية المشتركة بين العربية والتركية وتأثيرها في وفي تعليم العربية للطلبة الأترالك، بحث منشور ضمن لهن أعمال مؤتمر النقد الأدبي الخامس عشر "لاتربه لتراث اللغوي والنقدي العربي في الآداب العالمية"، الأردن:

$$
\text { جامعة اليرموك، يوليو، } 10 \text { • بrم. }
$$

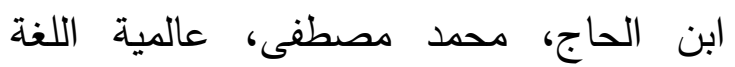
العربية، بحث منشور ضمن كتاب اللغة العربية وتحديات العصر "القرن العشرين"، تونس: المنظمة العربية للتربية والثقافة والعلوم، 997 (م. حجازي، محمود فهمي، دور وسائل الإعلام في التتمية اللغوية، القاهرة: مجلة مجمع اللغة العربية، ع .
قائمة المصادر والمراجع

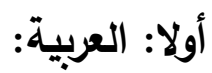
إبراهيم، أرسل، التطور الدلالي في الكلمات العربية المقترضة في اللغة الملايوية، بحث تكميلي لمتطلبات نيل درجة الماجستير غير منشور، ماليزيا: الجامعة الإسلامية العالمية، 990 ام. إبراهيم، سمير، معجم الألفاظ العربية في اللغة الزمانه

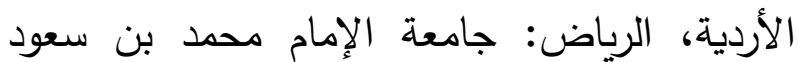

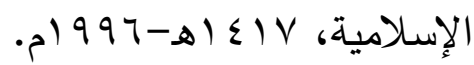
إبراهيم، مجدي حاج وآخرون، اللغة العربية في

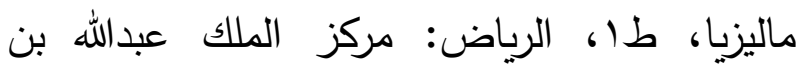

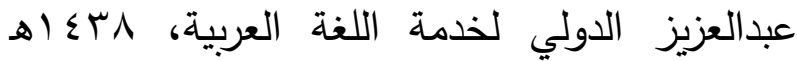
$.5 r+1 \mathrm{~L}$ أحمد، مواهب، أثر اللغة العربية في لغات غرب أفريقيا "لغة الهوسا أنموذجًا"، بحث منشور ضرهن أعمال مؤتمر النقد الدولي الخامس عشر :التراث اللغوي والأدبي والنقدي العربي في الآداب العالمية"،

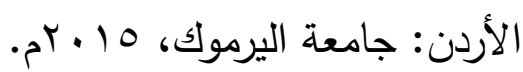

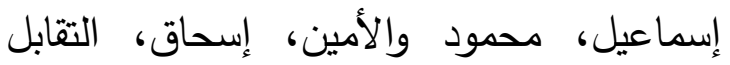
اللغوي وتحليل الأخطاء، طا، جامعة الملك سعود،

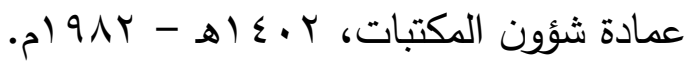
إنجلمان، دوزي، معجم المفردات الإسبانية والبرتغالية المشتقة من العربية، تعريب: نهاد الموسى، عمان: دار الفكر ، .919 ام. أنيس، إبراهيم، دلالة الألفاظ، طء، القار القاهرة: مكتبة الأنجلو المصرية، • 91 ام. 
الداية، فايز، علم الدلالة العربي " النظرية والتطبيق"، طץ، دمشق: دار الفكر، 997 (م. الراجحي، عبده، علم اللغة التطبيقي وتعليم اللغة، الرياض: جامعة الإمام محمد بن سعود

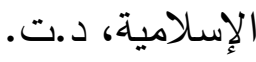

ريتشاردز ، جاك وآخرون، معجم لونجمان لتعليم اللغات وعلم اللغة التطبيقي، ترجمة: محمود حجازي ورشدي طعيمة، طا، مصر: الثركة المصرية

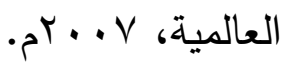
سلغا، حامس زكيا، قاموس الطلاب (الإنجليزية

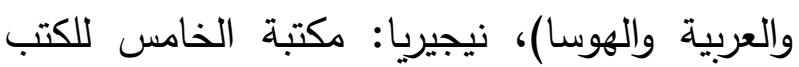

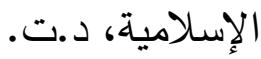

سلوم، داود، أثر اللغة العربية في اللغات

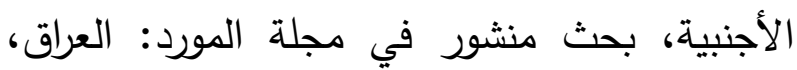

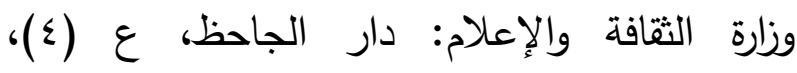
.

السيوطي، جلال الدين عبدالرحمن، المزهر في

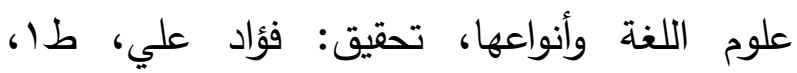

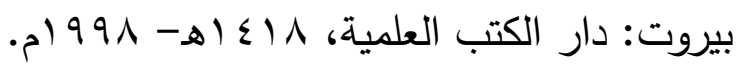
شعبان، إبراهيم، التأثير والتأثر بين اللغة العربية واللغة التركية، بحث منشور ضمن كتاب اللغة العربية في تركيا، طا، الرياض: مركز الملك عبدالله

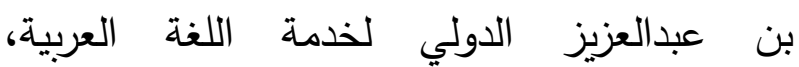

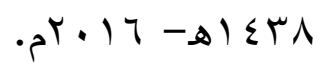

حجازي، مصطفى، مجم سياقي للكلمات

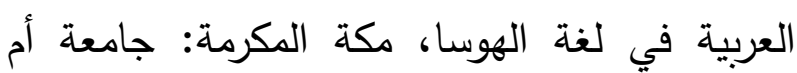
القرى، 7 • ـ أهـ

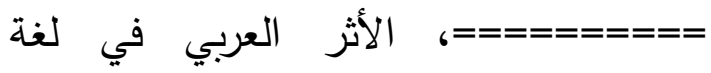
الهوسا "أنموذج من تأثير الأمثال العربية"، القاهرة:

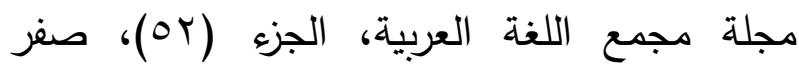

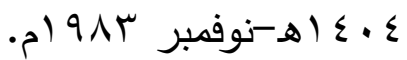

㳊 الكلمات العربية في لغة الهوسا، القاهرة: مجلة مجمع

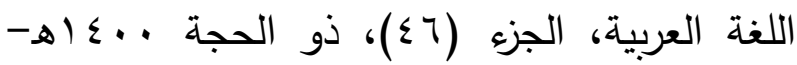

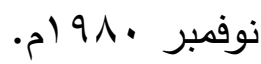

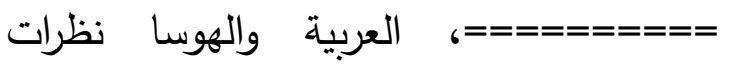
تقابلية، مكة المكرمة: جامعة أم القرى، د.ت.

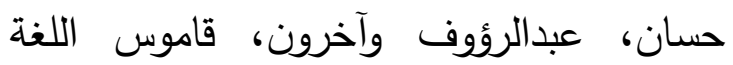
الملايوية- اللغة العربية، طا، ماليزيا: أكسفورد

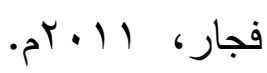
حسين، آييك، تأثير اللغة العربية في اللغة الإندونيسية ودعوة الثباب المسلم للحفاظ على لغة لغة لغن دينه الحنيف، مجلة الإصلاح، السنة (1) (1)، العدد

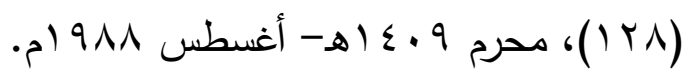
حقي، سهيل صابان، معجم الألفاظ العربية في اللغة التركية، طا، الرياض: جامعة الإمام محمد بن سعود الإسلامية، بTگ اله. الحموي، أحمد بن محمد، غمز عيون البصائر

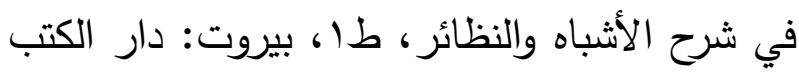

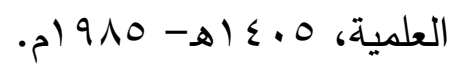


ماجستير غير منشورة، الجامعة الإسلامية: المدينة المنورة، بس الهـ

عبدربه، نصر ، تدريس اللغة من خلال نظرية التواصل الاجتماعي الثقافي، بحث منشور في أعمال مؤتمر اتجاهات حديثة في تعليم العربية لغة ثانية، الرياض: جامعة الملك سعود- معهد اللغويات

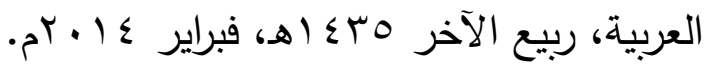
علي، عاصم، التداخل اللغوي وأثره في تعلم اللغة الأجنبية لغير الناطقين بها، بحث منشور ضمن أعمال المؤتمر الدولي الأول لتعليم العربية "الأنساق اللغوية والسياقات الثقافية في تعليم اللغة العربية"، الأردن: الجامعة الأردنية، ع ا ـ بم، المجلد (1). أبو عمشة، خالد، النظائر المخادعة في تعليم العربية للناطقين بغيرها، مقال متاح على موقع منتدى مجمع اللغة العربية على الشبكة العالمية: http://www.m-a-arabia.com غازي، أنعام الحق، الاقتراض اللغوي من العربية إلى الأردية، رسالة ماجستير غير منشورة، إسلام آباد: الجامعة الإسلامية العالمية، وAV ام. فتحي، سويفي، أثر التقابل اللغوي في تعليم العربية لغير الناطقين بها، مقال متاح على الموقع: http://www.alukah.net الفيروزابادي، مجد الدين أبو طاهر، القاموس المحيط، تحقيق: مكتب التراث، طه، بيروت:

$$
\text { مؤسسة الرسالة، جrع اهـ - } 0 \text {. . بrم. }
$$

شعراوي، إحسان ويونس، فتحي، مقدمة في البحث التربوي، القاهرة: دار الثقافة للطباعة والنشر ، - ) $9 \wedge \varepsilon$

الشهابي، الأمير مصطفى، المصطلحات العلمية في اللغة العربية في القديم والحديث، طب، دمشق: المجمع العلمي العربي، ؟مبا اهـ- 970 (م. الصالح، صبحي، دراسات في فقه اللغة، ط. 1، بيروت: دار العلم للملايين، سم 9 ام. طعيمة، رشدي، تعليم اللغة اتصاليًا بين المناهج والإستراتيجيات، منشورات المنظمة الإسلامية للتربية والعلوم والثقافة (إيسكو)، 7 . . ץ.م. ظاظا، حسن، اللسان والإنسان، القاهرة: دار

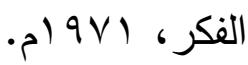
عبدالحميد، علي، مشكلات تعليم اللغة العربية لغير الناطقين بها: كليات الإلهيات في تركيا أنموذجًا "قلب الصف هو الحل"، بحث منشور ضمن كتاب اللغة العربية في تركيا، طا، الرياض: مركز الملك عبدالله بن عبدالعزيز الدولي لخدمة اللغة العربية، . عبدالسلام، أحمد شيخ، مدخل إسلامي إلى إلى اللغويات العامة، طا، ماليزيا: مركز الأبحاث بالجامعة الإسلامية العالمية، . . . بم. عبدالعزيز، محمد، مدخل إلى اللغة، مصر: دار الوفاء للطباعة، raA ام. عبدالله، علي، إعداد قائمة ثلاثية للكلمات العربية الثائعة (عربي- إنجليزي- هوسا)، رسالة 
عبدالله بن عبدالعزيز الدولي لخدمة اللغة العربية، م

مجموعة باحثين، اللغة العربية في إندونيسيا، طا، الرياض: مركز الملك عبدالله بن عبدالعزيز

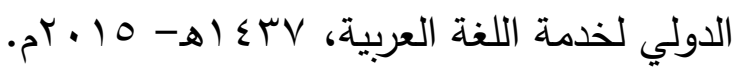
محفوظ، حسين، أثر اللغة العربية في الشعوب لهبه الشرقية، الإعلام- اللهجات في إيران وتركية والهند، بحث منشور في مجلة المورد: العراق، مجلد (9)،

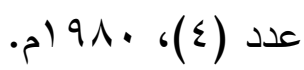
محمد، عبدالرزاق، ملاحظات عن الألفاظ الهوسوية المقترضة من اللغة العربية، بحث منشور في المجلة العربية للدراسات اللغوية: معهد الخرطوم الدولي للغة العربية، المجلد السابع، العدد (Y/l)،

$$
\text { رجب } 9 \text {. ؛ (اه- فبراير } 919 \text { ام. م. }
$$

المربوي ، محمد إدريس، قاموس إدريس المربوي

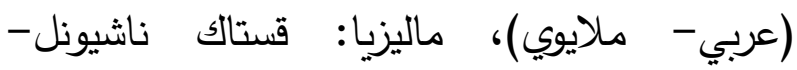

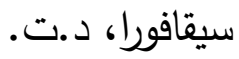

المسكين، تيجاني وآخرون، اللغة العربية في نيجيريا، طا، الرياض: مركز الملك عبدالله بن

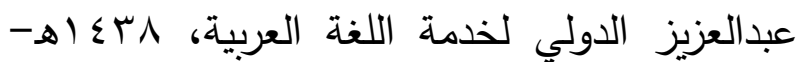
$.5+1 V$

ملك، خالق، تعليم اللغة العربية في باكستان، طا، بحث منشور ضمن كتاب اللغة العربية في باكستان، الرياض: مركز الملك عبدالله بن عبدالعزيز

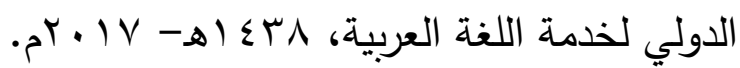

القاسمي، علي، علم المصطلح أسساه النظرية وتطبيقاته العملية، طا، بيروت: مكتبة لبنان

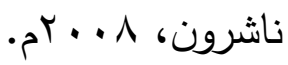

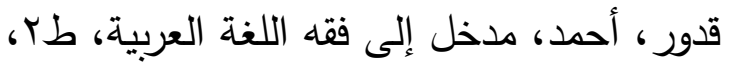
دمشق: دار الفكر، 999 (م. قدور، أحمد، مبادئ اللسانيات، دمشق: دار لمخر

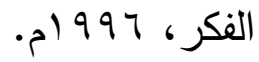
القضاة، محمد والعمري، فاطمة، أثر اللغة الأم في تعلُم اللغة الثانية: العربية للناطقين بغيرها أنموذجًا، بحث منشور في مجلة دراسات، العلوم

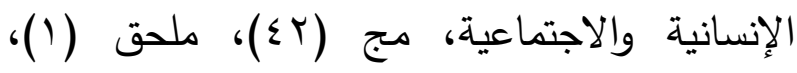
$.0+10$ الكرمي، حسن، قاموس الهنجد الهادي إلى لغة

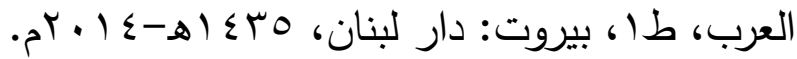
الكشو، رضا، توظيف اللسانيات في تعليم اللغات، مكة المكرمة: من منشورات مجمع اللغة

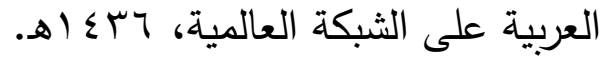
مجمع اللغة العربية بالقاهرة، المعجم الوسيط، تركيا: المكتبة الإسلامية، د.ت. مجموعة باحثين، اللغة العربية في باكستان، تحرير: إنعام الحق غازي، طا، الرياض: مركز

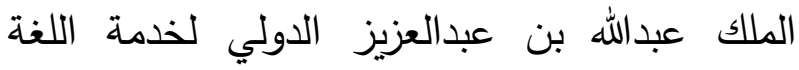

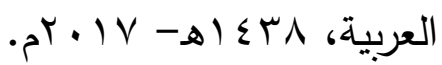
مجموعة باحثين، اللغة العربية في تركيا،

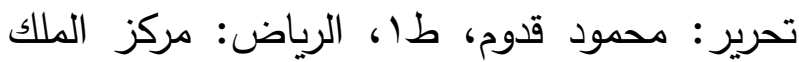


الندوي، عبدالله، نظام اللغة الأردية الصوتي

واللفظي والنحوي، دراسة أسلوبية، مكة المكرمة:

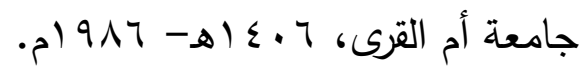

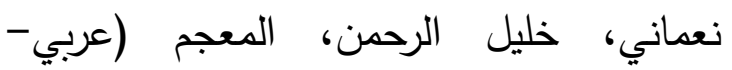
أرودو)، دار الاشاعت: كراجي، ع 9 (م.

هوكلكلي، قدرية، إجادة الترجمة بين العربية

والتركية انبثاقًا من الإشكالات الثقافية، بحث منشور

ضمن كتاب اللغة العربية في تركيا، طاه، الرياض: مركز الملك عبدالله بن عبدالعزيز الدولي لخدمة اللغة

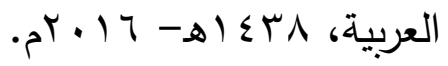

وافي، علي، علم اللغة، مصر: دار نهضة

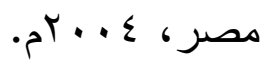

\section{ثانيا: الأجنبية}

Beg, M. A. J., ( 1979). Arabic Loan- Word in Malay: A Comparative Study, Kuala Lumpur: The University of Malaya Press.

Burkholder, Michèle, (2015). Les Faux-Amis : Investigating Lexico-Semantic Ambiguity Across Two Languages, University of Ottawa, Proceedings of the Annual Conference of the Canadian Linguistic Association. At: claacl.ca/wp-content/uploads/Burkholder.pdf.

Camel Heah Lee Hasia, (1989). The Influence of English an Lexical of Bahasa Malaysia, Kuala Lumpur: Dewan Bahasa dan Pustaka.

Cook, Guy, (2015). Translation in Language Teaching, Oxford: Oxford University Press,

Hamdan, Abd Rahman, (1998).Tulisan Jawi Ke Arah Penggunaan Dan Pengukuhan Yang Meluas. Seminar Bahasa Melayu dan Pembangunan Insan.

Lado, R, (1957). Linguistics Across Culture: Applied Linguistics for Language Teachers, University of Michigan press: Ann Arbor.

$M^{a}$ Luisa Roca-Varela, (2006). Intralingual False Friends: British English and American English As a Case in Point. University of Santiago de Compostela, Available at: https://www.srcf.ucam.org/camling/proceedings/rocavarela.

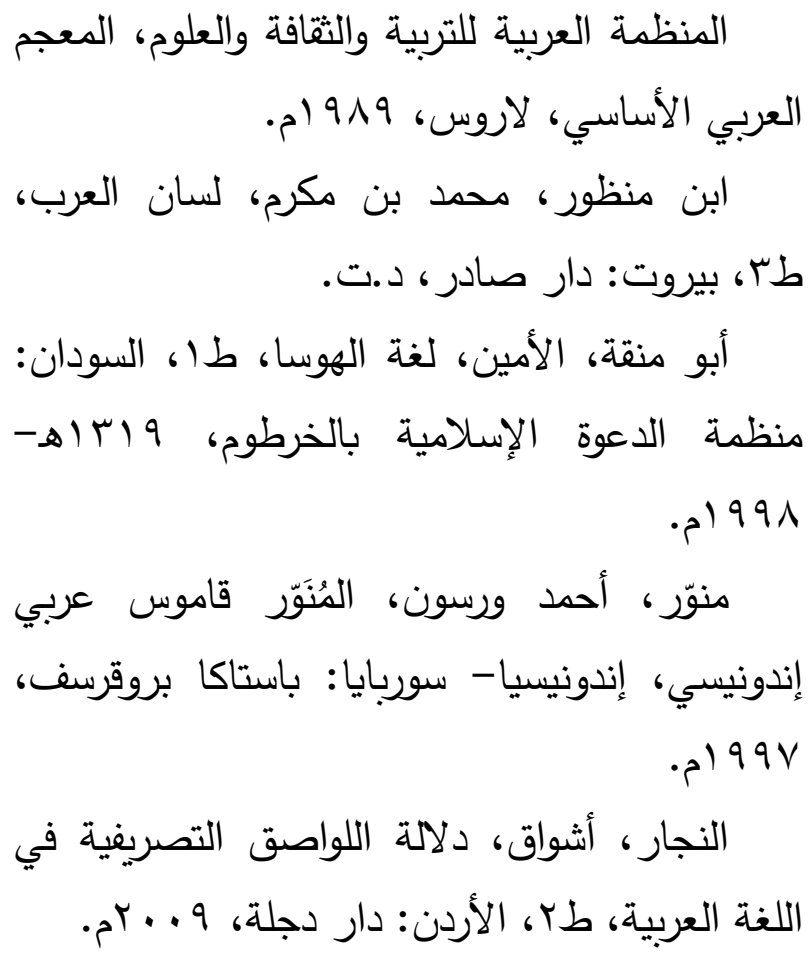

$M^{a}$ Luisa Roca-Varela, (2011). Teaching and Learning "False Friends" A Review of Some Useful Resources, University of Santiago de Compostela, Encuentro 20, ISSN1989-0796

https://ebuah.uah.es/dspace/bitstream/handle/10017/10108/tea ching_roca_ENCUENT RO_2011.pdf?.

María Luisa Roca-Varela, (2014). Faux Amis in Speech and Writing: a Corpus-Based Study of English False Friends in the Production of Spanish Student, Recent Advances in Corpus

DOI: 10.1163/9789401211130_014

Linguistics,VOL.78,

M. Martha, Lengeling,( 1995). Universidad De Guanajuato, True Friends and False Friends, Volume 19, Number 2, Convention Issue.

NYS Statewide Language Rbern (2015). False Cognates: English/ Spanish, 2015, The University of The State if New York/ Albany, NY 12234.

O, Neill, R, (1998), Language Acquisition and CLT. Retrieved June 21, 2010 from: http://www.btinternet.com/ ted . power/ es 10412.html.

O'Neill, Maria and Catalá, Montse, False Friends: A Historical Perspective and Present Implications for Lexical Acquisition, Universitat de Lleida, Available at: http://www.raco.cat/index.php/bells/article/download/102791/ 149196.

Pedro J, Chamizo-Domínguez,( 2008). Semantics and Pragmatics of False Friends, London: New York Routledge. 
Pedro J. at all, Nottingham NG7 2RD, UK Received 22 September 2000; received in revised form 14 January 2002; accepted 15 January 2002. Journal of Pragmatics 34 (2002) 1833-1849. At: www.elsevier.com/locate/pragma

Szpila, G. 2006. False Friends in Dictionaries. Bilingual False Cognates lexicography in Poland International Journal of Lexicography 19/ 1, 73-97, https://doi.org/10.1093/ijl/eci041.

The Problem of False Friends in Learner Language Evidence from Tow Learner Corpora, Santiago University Learner of English, Published Research in: www.spertus.es.

Tycová, Lenka.( 2012). Towards a New False Friends Dictionary, Bachelor's Diploma Thesis, Masaryk University; Faculty of Arts.

Veisbergs, Andrejs, (1996). False Friends Dictionaries: A Tool for Translators or Learners or Both, University of Latvia. Available at: https://www.tib.eu/en/search/id/BLCP\%3ACN017605082/

Yaşar Avcı, (2005). Arapça Kökenli Osmanlica Sözcükler, s. 7; bkz. Türk Dil Kurumu Türkçe Sözlük, Ankara,3448 s. 1-7.

$$
\text { ثالثا: المواقح الإلكترونية }
$$

booksandjournals.brillonline.com/content/.../b97894012111 30s014.

fac.ksu.edu.sa/sites/default/files/6_28.pd.

http://www.alukah.net.

http://www.btinternet.com/

http://www.raco.cat/index.php/bells/article/download/10279 $\underline{1 / 149196 .}$

https://doi.org/10.1093/ijl/eci041.

https://www.srcf.ucam.org/camling/proceedings/rocavarela.

https://www.tib.eu/en/search/id/BLCP\%3ACN017605082/

www.m-a-arabia.com .

www.spertus.es.

www.elsevier.com/locate/pragma

-https://www.englisch-hilfen.de/en/words/false_friends.htm cla-acl.ca/wp-content/uploads/Burkholder.pdf. 


\title{
False Friends in Foreign Language Teaching and Learning: Arabic as an Example
}

\author{
Saleh bin Ayad al - Hagory \\ King Abdulaziz University
}

\begin{abstract}
This research aims at discussing the false friends in teaching and learning Arabic. This is shown by means of a theoretical approach which explicates the false friends concept origin, and types. It also presents the western implication of the false friends, their origin in the languages, as well as their influence upon teaching and learning a language. The research then presents an applied approach of those false friends in five languages, compared to the Arabic language, namely: Urdu, Indonesian, Turkish, Malay, and Hosa based on the analytical descriptive approach. The false friends are mostly common among languages that have relationship - or from the same language family- and are less common in the diverged languages. Furthermore, false friends emerged as a result of borrowing among languages, by hairing an effect on teaching Arabic to non-native speakers of Arabic in five languages.
\end{abstract}

Key Words: False Friend - Language Borrowing - Linguistic Intermixture . 